\title{
Article \\ CgEnd3 Regulates Endocytosis, Appressorium Formation, and Virulence in the Poplar Anthracnose Fungus Colletotrichum gloeosporioides
}

\author{
Xiaolian Wang ${ }^{\dagger}$, Dongxiao Lu ${ }^{\dagger}$ and Chengming Tian * \\ The Key Laboratory for Silviculture and Conservation of Ministry of Education, College of Forestry, Beijing \\ Forestry University, Beijing 100083, China; XiaolianWang94@163.com (X.W.); ludongxiaou@163.com (D.L.) \\ * Correspondence: chengmt@bjfu.edu.cn \\ † These authors contributed equally to this work.
}

Citation: Wang, X.; Lu, D.; Tian, C. CgEnd3 Regulates Endocytosis,

Appressorium Formation, and

Virulence in the Poplar Anthracnose Fungus Colletotrichum gloeosporioides. Int. J. Mol. Sci. 2021, 22, 4029.

https://doi.org/10.3390/ijms22084029

Academic Editor: Shawn

A. Christensen

Received: 16 March 2021

Accepted: 3 April 2021

Published: 14 April 2021

Publisher's Note: MDPI stays neutral with regard to jurisdictional claims in published maps and institutional affiliations.

Copyright: () 2021 by the authors. Licensee MDPI, Basel, Switzerland. This article is an open access article distributed under the terms and conditions of the Creative Commons Attribution (CC BY) license (https:// creativecommons.org/licenses/by/ $4.0 /)$.

\begin{abstract}
The hemibiotrophic ascomycete fungus Colletotrichum gloeosporioides is the causal agent of anthracnose on numerous plants, and it causes considerable economic losses worldwide. Endocytosis is an essential cellular process in eukaryotic cells, but its roles in C. gloeosporioides remain unknown. In our study, we identified an endocytosis-related protein, $\mathrm{CgEnd} 3$, and knocked it out via polyethylene glycol (PEG)-mediated protoplast transformation. The lack of $C g E n d 3$ resulted in severe defects in endocytosis. C. gloeosporioides infects its host through a specialized structure called appressorium, and $\Delta C g E n d 3$ showed deficient appressorium formation, melanization, turgor pressure accumulation, penetration ability of appressorium, cellophane membrane penetration, and pathogenicity. $\mathrm{CgEnd3}$ also affected oxidant adaptation and the expression of core effectors during the early stage of infection. CgEnd3 contains one EF hand domain and four calcium ion-binding sites, and it is involved in calcium signaling. A lack of $C g E n d 3$ changed the responses to cell-wall integrity agents and fungicide fludioxonil. However, $\mathrm{CgEnd} 3$ regulated appressorium formation and endocytosis in a calcium signaling-independent manner. Taken together, these results demonstrate that $C g E n d 3$ plays pleiotropic roles in endocytosis, calcium signaling, cell-wall integrity, appressorium formation, penetration, and pathogenicity in C. gloeosporioides, and it suggests that $C g E n d 3$ or endocytosis-related genes function as promising antifungal targets.
\end{abstract}

Keywords: anthracnose; Colletotrichum gloeosporioides; appressorium; endocytosis; pathogenicity; calcium signaling

\section{Introduction}

Colletotrichum species are known to cause anthracnose on a wide variety of host plants, including cereals, fruit plants, legumes, vegetables, fruit trees, and forest trees [1]. Poplar (Populus $\times$ beijingensis) is among the most commonly cultivated forestry species in China, and the hemibiotrophic fungus Colletotrichum gloeosporioides is the causal agent of poplar anthracnose, which causes considerable economic losses [2,3]. This fungus forms a specialized infection structure, called an appressorium, which correlates strongly with pathogenicity [3-5]. The poplar anthracnose infection initiates with the adhesion of the conidium on the leaf surface; then, germ tubes form from the germinated conidium [6]. Various host signals, including epicuticular waxes, cutin monomers, hydrophobicity, hardness, and topography, are recognized at this stage, and appressorium is subsequently formed at the tip of the germ tube [7]. A mature appressorium mechanically and enzymatically ruptures the cuticles of leaves. Then, the penetration peg at the infection site differentiates into the primary hyphae, which grow into the epidermal cells, and secondary hyphae, which subsequently spread through the underlying mesophyll cells and develop necrotic lesions [6].

Appressoria are specialized infection structures in many phytopathogens, which play a key role in the penetration of the host cuticle. There are many studies that focus on the 
regulation of appressorium development in model pathogenic fungi, including Magnaporthe oryzae, Botrytis cinerea, rust fungi, Ustilago maydis, and Colletotrichum species [5]. At the early stage of appressorium development, cell surface sensors recognize the host signals and subsequently activate downstream pathways, such as the Cyclic adenosine monophosphate (cAMP) pathway and mitogen-activated kinase pathway [8-11]. In addition to the perception of host signals, cell cycle control plays an important role in appressorium development. In M. oryzae and $U$. maydis, the intervention of the cell cycle checkpoint during mitosis prevented both appressorium development and autophagy [12,13]. Autophagy in germinated conidia is a prerequisite for the degradation of intracellular contents, which contributes to the accumulation of turgor pressure [14]. During the maturation of appressoria, the inner side of the appressorium cell wall forms a melanin layer, which provides the structural rigidity of appressorium [15]. Mature appressorium mechanically and enzymatically ruptures the cuticle of the host surface, and penetration pegs form subsequently. The turgor pressure provides the essential driving force that enables the fungal peg to mechanically penetrate the host tissue [16], and the melanin deposit in the cell wall of appressorium is essential for the maintenance of high turgor pressure [17,18]. In Colletotrichum higginsianum, random insertional mutagenesis identified six mutants that were impaired in appressoria melanization, and five out of six mutants are completely unable to penetrate living host epidermal cells, ethanol-killed leaves, or cellophane membranes [19]. In Colletotrichum orbiculare, transcripts of three melanin biosynthesis genes, PKS1, SCD1, and THR1, are increased during appressorium differentiation [20]. The deletion of PKS1, SCD1, and THR1 affects the melanization of appressoria, and it results in the penetration defect and decreased virulence [21-23]. In C. gloeosporioides, the deletion of $C g S c d 1$ results in complete loss of melanization in appressoria, impaired infection ability of nonmelanized appressoria, and the virulence of $\Delta C g S c d 1$ is significantly decreased in tomato and lime fruits [24]. These studies indicated that the melanin deposition in appressoria plays a vital role in penetration and pathogenicity. In C. higginsianum, C. orbiculare, and M. oryzae, a variety of effectors are secreted during the infection process to suppress host immunity [25-27]. Collectively, the formation of appressorium and subsequent penetration involves a subset of molecular processes [28], and the characterization of appressorium-related genes is vital for the identification of these molecular mechanisms.

In eukaryotic cells, the intracellular calcium ion plays an important role in cellular processes, and it is required for the response to diverse environmental cues [29]. Cytosolic $\mathrm{Ca}^{2+}$ binds to and activates the protein calmodulin, which contains the $\mathrm{Ca}^{2+}$-binding motif $\alpha$-helix E loop $\alpha$-helix F (EF) hands, and subsequently activates calmodulin-dependent enzymes, such as calcineurin, calmodulin-dependent protein kinases, and histone deacetylases [30,31]. Calcium signaling plays crucial roles in stress tolerance, sporulation, cell-wall integrity, and pathogenicity in fungi [32-34]. In M. oryzae, the calcineurin-responsive transcription factor, $\mathrm{MoCrz1}$, regulates calcium ion response, vegetative growth, cell-wall integrity, and pathogenicity [35]. $\mathrm{VdCrz1}$ regulates cell-wall integrity, microsclerotia formation, and pathogenicity in Verticillium dahliae [36]. BcCrz1 is involved in stress response, cell-wall integrity, sclerotia formation, and pathogenicity in B. cinerea [37]. In U. maydis, the deletion of endoplasmic calcium ATPase Eca1 results in severe growth and morphology defects [38]. In M. oryzae, the primary functions of almost all known calcium-signaling proteins in the genome are characterized using the high-throughput RNA silencing system, and the results show that 26,35 , and 15 out of the 37 calcium signaling-related genes are involved in vegetative growth, sporulation, and pathogenicity, respectively [39].

In the eukaryotic cell, the optimal growth requires the elaboration of responses to the extracellular environment, and endocytosis is an important process for the maintenance of cellular homeostasis. Endocytosis is an important cellular process in the eukaryotic cell, which internalizes membrane proteins and macromolecules from the extracellular environment [40]. Nevertheless, the molecular studies of endocytosis in fungi has only proceeded in last two decades, with the development of the fluorescent dye N-(3triethylammoniumpropyl)-4-(p-diethylaminophenylhexatrienyl)-pyridinium 2Br (FM4-64) 
as an indicator of endocytosis [41]. The systematic mechanism of endocytosis has been well illuminated in the yeast, Saccharomyces cerevisiae, such as the role of END4/SLA2 [42,43]. In any case, Snf1 acts as a nutrient-sensing regulator of endocytosis [44]. In addition, End3p is a key regulator of the organization of cortical actin cytoskeleton and endocytosis, and a lack of End3p affects the internalization of a variety of yeast plasma membrane proteins [45,46]. End3p is also required for the correct distribution of chitin at the cell surface [47]. Despite the well-developed network of endocytosis in yeast, the mechanisms of endocytosis in Colletotrichum species are basically unknown. In this study, we identified CgEnd3 in C. gloeosporioides, which isorthologous to yeast End3p. In this study, $C g E n d 3$ is a key regulator of endocytosis, and the deletion of $\mathrm{CgEnd} 3$ resulted in the significantly decreased ability of appressorium formation and penetration. The pathogenicity of the $\mathrm{CgEnd} 3$ deletion mutant is significantly decreased compared with that of the wild type (WT), which is attributed to the defects in oxidant adaptation and the expression of core effectors. Our study firstly reports on the role of $C g E n d 3$ in calcium signaling. In addition, $C g E n d 3$ plays a pleiotropic role in the response to cell wall integrity agent calcofluor white (CFW), oxidative stress, and fungicide fludioxonil.

\section{Results}

\subsection{CgEnd3 Is Required for Endocytosis}

Endocytosis is a basic cellular process in eukaryotic cells, which internalizes membrane proteins and macromolecules from the extracellular environment. To determine the molecular functions of $C g E n d 3$ in C. gloeosporioides, $C g E n d 3$ deletion mutants were obtained by replacing the encoding gene with a Sur cassette. Subsequently, the full-length sequence of $C g E n d 3$ was reintroduced into the $\Delta C g E n d 3$ for complementation assay (Figure S2). FM4-64 is a ubiquitous tool in analyzing endocytosis and vesicle trafficking in living fungi and plants. To determine whether $C g E n d 3$ is required for the normal endocytosis process, the hyphal blocks from WT, $\triangle C g E n d 3$, and $\triangle C g E n d 3 / E N D 3$ were inoculated on Potato Dextrose Agar (PDA)-coated glass slides. Then, each strain was stained with $5 \mu \mathrm{M}$ of the lipophilic dye FM4-64 and the internalization of FM4-64 was subsequently observed under a fluorescence microscope. At $0 \mathrm{~min}$, the dye accumulated specifically at the plasma membrane of WT and $\Delta C g E n d 3$, indicating that the internalization of the dye had not begun. At $10 \mathrm{~min}$, punctate and patchy structures begin to appear at both the plasma membrane and cytoplasm in WT and $\Delta C g E n d 3 / E N D 3$, indicating the rapid uptake of the dye and functional endocytosis process in hyphae. At 20 and $30 \mathrm{~min}$, the dye was dispersed in the whole hyphae of WT and $\Delta C g E n d 3 / E N D 3$. In contrast, only a few dots appeared at the plasma membrane of $\Delta C g E n d 3$ at $20 \mathrm{~min}$, and the internalization of FM4-64 only became obvious at $30 \mathrm{~min}$ (Figure 1A). Moreover, the florescence intensity in the cytoplasm of $\Delta C g E n d 3$ was significantly decreased, compared with that of the WT and $\triangle C g E n d 3 / E N D 3$ at different time points (10-30 min) (Figure 1B). To further demonstrate the function of $C g E n d 3$ in endocytosis, the endocytosis inhibitor, Latruncuin B (LatB), was applied in this study. The results showed that the pattern of FM4-64 internalization was similar between $\Delta C g E n d 3$ and LatB-treated WT (Figure 1A,B). C. gloeosporioides formed a specialized infection structure, called appressorium, which plays a vital role in pathogenicity. To determine whether endocytosis is an essential factor for appressorium formation, germinated conidia was exposed to $0.1 \mu \mathrm{g} / \mathrm{mL}$ LatB for $30 \mathrm{~min}$. The results showed that LatB treatment significantly affected the formation of appressorium in WT (Figure 1C,D). Collectively, these results showed that $C g E n d 3$ played an important role in endocytosis, and normal endocytosis during germination was required for appressorium formation in C. gloeosporioides. 
A

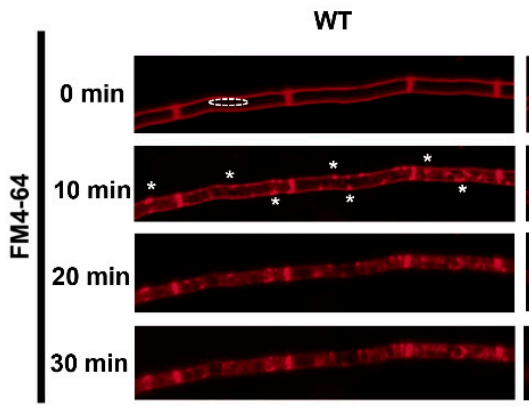

B

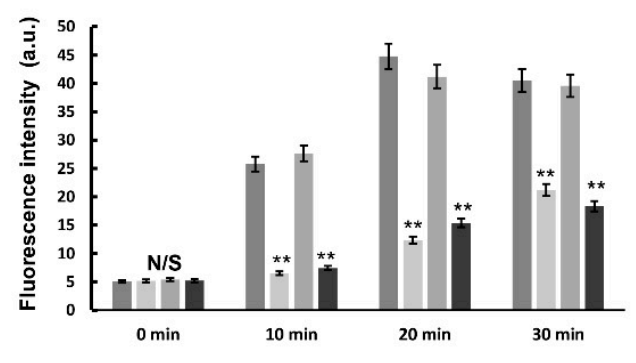

$\varpi W T=\Delta$ CgEnd3 $₫ \Delta$ CgEnd3/END3 $\backsim W T+0.1 \mu \mathrm{g} / \mathrm{ml}$ LatB
$\Delta$ CgEnd3

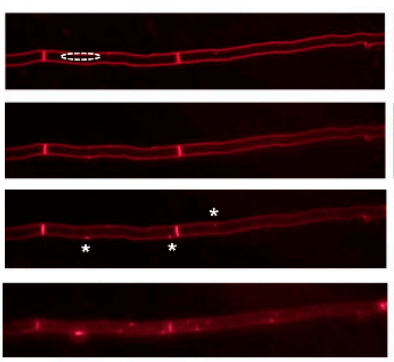

C

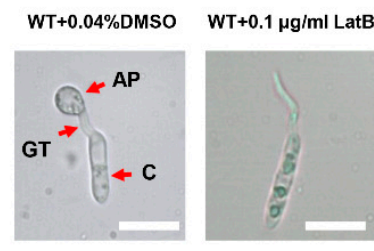

$\Delta$ CgEnd3/END3

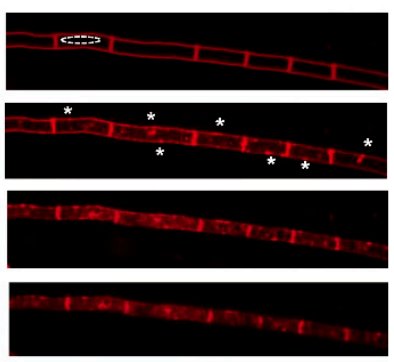

WT+0.1 $\mu \mathrm{g} / \mathrm{ml}$ LatB

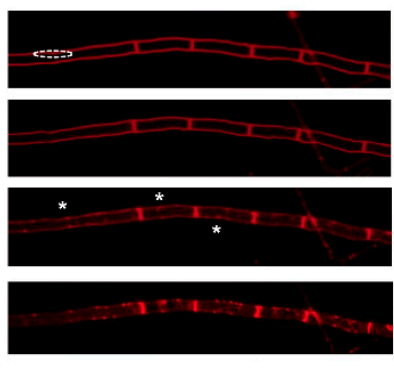

D

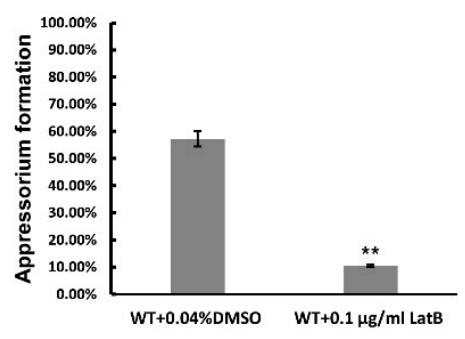

Figure 1. Involvement of $C g E n d 3$ in endocytosis. (A) Hyphal block from wild type (WT), $\Delta C g E n d 3$, and $\Delta C g E n d 3 / E N D 3$ were inoculated on Potato Dextrose Agar (PDA)-coated glass slides and cultured at $25^{\circ} \mathrm{C}$. At 2 days post inoculation (dpi), hyphae were stained using $0.5 \mu \mathrm{M} \mathrm{N}$-(3-triethylammoniumpropyl)-4-(p-diethylaminophenylhexatrienyl)-pyridinium 2Br (FM4-64), and images were photographed at different time points (0-30 min) using fluorescence microscope. In any case, hyphae from WT were treated with $0.1 \mu \mathrm{g} / \mathrm{mL}$ Latrunculin B (LatB) for $30 \mathrm{~min}$. The dotted frame indicates the region of cytoplasm, and the fluorescence intensity at each time point was quantified using ImageJ software. The white asterisks indicate site of endocytosis. This experiment was repeated three times. Bars $=10 \mu \mathrm{m}$. (B) Bar chart showing the mean fluorescence intensity in cytoplasm of each strain at different time points. Data from at least ten hyphae were collected at each time points from each strain. Error bars represent the standard deviations. Data were analyzed using Duncan's range test. Asterisks ** indicate statistically significant differences at $p<0.05$. a.u., arbitrary units. (C) Conidial suspensions $\left(10^{5}\right.$ conidia $\left./ \mathrm{mL}\right)$ from WT were inoculated on the hydrophobic side of Gel-bond membrane, water drops were replaced by $30 \mu \mathrm{L}, 0.1 \mu \mathrm{g} / \mathrm{mL}$ LatB at $3 \mathrm{hpi}$ for $30 \mathrm{~min}$, and the controls were treated with $0.04 \%$ dimethyl sulfoxide (DMSO). Each sample was washed with distilled water after treatment. Appressorium formation was imaged at $5 \mathrm{~h}$ post inoculation (hpi). This experiment was repeated three times. $\mathrm{AP}=$ appressorium. $\mathrm{GT}=$ germ tube. $\mathrm{C}=$ conidia. Bars $=10 \mu \mathrm{m}$. (D) Bar chart showing the rate of appressorium formation at 5 hpi. Error bars represent the standard deviations. Data were analyzed using Duncan's range test. Asterisks ** indicate statistically significant differences at $p<0.05$. N/S = difference not significant.

\subsection{Deletion of CgEnd3 Resulted in the Defect of Appressorium Formation, Melanization, Polarity, Penetration and Invasive Growth}

Since $C g E n d 3$ regulates endocytosis, and normal endocytosis during germination was required for appressorium formation in C. gloeosporioides, we then examined whether or not $\mathrm{CgEnd} 3$ was involved in the development of appressorium. Equal volumes $(30 \mu \mathrm{L})$ of conidial suspensions $\left(10^{5}\right.$ conidia/mL) from WT, $\Delta C g E n d 3$, and $\Delta C g E n d 3 / E N D 3$ were inoculated on the hydrophobic side of the Gel-bond membrane. At 9 hpi, WT and $\triangle C g E n d 3 /$ END3 formed numerous appressoria ( $>90 \%$ ); over $75 \%$ of the appressoria that was formed in WT and $\triangle C g E n d 3 / E N D 3$ were melanized. However, $\triangle C g E n d 3$ showed significantly decreased appressorium formation $(\approx 50 \%)$ compared with that of the WT, and only approximately $5 \%$ of appressoria were melanized (Figure 2A,B). Moreover, multiple germ tubes were observed in $\Delta C g E n d 3$ (Figure 2A). These results indicate that $C g E n d 3$ was required for appressorium formation, melanization, and polarity during germination. In previous studies, onion epidermal cells have been extensively used in the analysis of penetration ability in phytopathogenic fungi $[48,49]$. To test the penetration ability of 
appressoria in $\Delta C g E n d 3$, equal volumes $(30 \mu \mathrm{L})$ of conidial suspensions $\left(10^{5}\right.$ conidia $\left./ \mathrm{mL}\right)$ from WT, $\Delta C g E n d 3$, and $\Delta C g E n d 3 / E N D 3$ were inoculated on the onion epidermal cells (hydrophobic surface). The results show that $\Delta C g E n d 3$ displayed similar defects in appressorium formation and polarity during germination, compared with that on the Gel-bond membrane. The penetration rate of appressorium in $\Delta C g E n d 3$ was significantly decreased compared with that of the WT and $\Delta C g E n d 3 / E N D 3$, and $\Delta C g E n d 3$ developed stunted infection hyphae compared with the WT (Figure 2C,D). These results indicated that $C g E n d 3$ plays an important role in appressorium formation, melanization, polarity, penetration, and invasive growth.

A
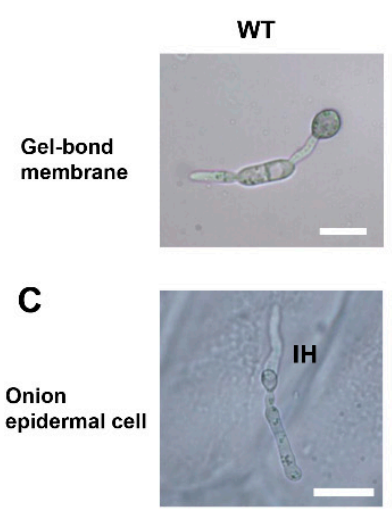

E

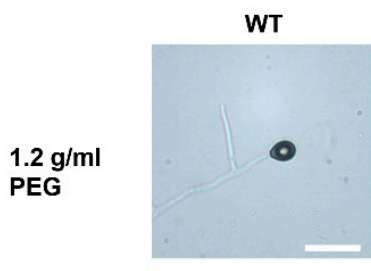

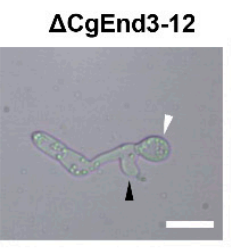
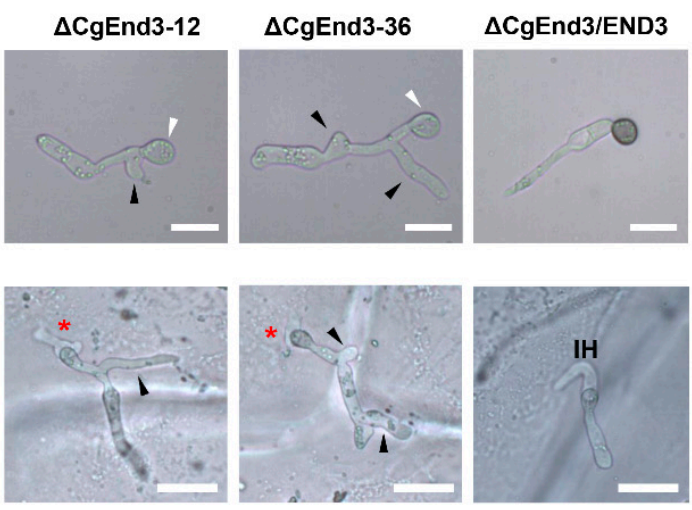

\section{D}
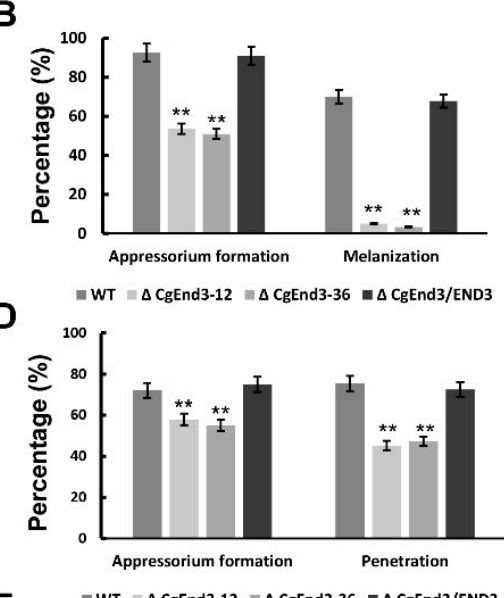

$\mathbf{F}$
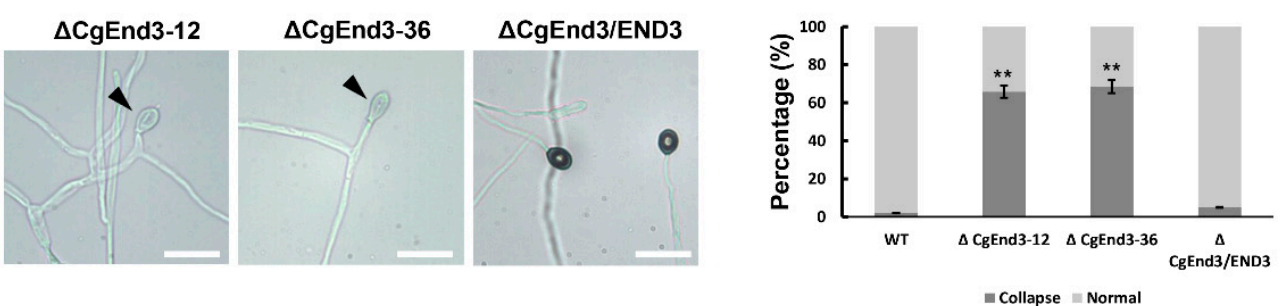

Figure 2. Appressorium formation, penetration and turgor pressure test. (A) Equal volumes $(30 \mu \mathrm{L})$ of conidial suspensions $\left(10^{5}\right.$ conidia/mL) from WT, $\Delta C g E n d 3$, and $\Delta C g E n d 3 / E N D 3$ were inoculated on the hydrophobic side of the Gel-bond membrane. Images were pictured at $9 \mathrm{hpi}$. White arrow indicates the nonmelanized appressorium. This experiment was repeated three times. Black arrow indicates the branched germ tube. Bars $=10 \mu \mathrm{m}$. (B) Bar chart showing the percentage of appressorium formation and melanization at 9 hpi in (A). Error bars represent the standard deviations. Data were analyzed using Duncan's range test. Asterisks ** indicate a statistically significant differences at $p<0.05$. (C) Appressorium formation and penetration of WT, $\Delta C g E n d 3$, and $\Delta C g E n d 3 / E N D 3$ on onion epidermal cell at 9 hpi. This experiment was repeated three times. $\mathrm{IH}=$ infection hyphae. Red asterisk indicates the stunted infection hyphae. Black arrow indicates the branched germ tube. Bars $=10 \mu \mathrm{m}$. (D) Bar chart showing the appressorium formation and penetration rate in WT, $\Delta C g E n d 3$, and $\Delta C g E n d 3 / E N D 3$ on onion epidermal cell at 9 hpi. Error bars represent the standard deviation. Data were analyzed using Duncan's range test. Asterisks ** indicate statistically significant differences at $p<0.05$. (E) The turgor pressure of appressorium from WT, $\Delta C g E n d 3$, and $\Delta C g E n d 3 / E N D 3$ were tested using $1.2 \mathrm{~g} / \mathrm{mL}$ polyethylene glycol (PEG) 4000. Black arrow indicates the collapsed appressorium. This experiment was repeated three times. Bars $=10 \mu \mathrm{m}$. (F) Bar chart showing the percentage of normal or collapsed appressorium in WT, $\Delta C g E n d 3$, and $\Delta C g E n d 3$ /END3 under the treatment of PEG 4000 for $10 \mathrm{~min}$. Error bars represent the standard deviations. Data were analyzed using Duncan's range test. Asterisks ** indicate statistically significant differences at $p<0.05$.

\subsection{Turgor Pressure Is Decreased in $\triangle C g E n d 3$}

Melanin, in the appressoria of most plant pathogenic fungi, allows for the buildup of turgor pressure, and turgor pressure provides the essential driving force that enables the fungal peg to rupture the host cuticle [16]. In this study, the melanization of appres- 
soria in $\Delta C g E n d 3$ was impaired significantly, and the penetration rate of $\Delta C g E n d 3$ was also decreased. To determine whether turgor pressure in $\Delta C g E n d 3$ was decreased, turgor pressure was tested using a high concentration of PEG $4000(1.2 \mathrm{~g} / \mathrm{mL})$. Conidial suspensions $\left(10^{5}\right.$ conidia $\left./ \mathrm{mL}\right)$ from WT, $\Delta C g E n d 3$, and $\Delta C g E n d 3 / E N D 3$ were inoculated on the hydrophobic side of the Gel-bond membrane. At $12 \mathrm{hpi}$, the water drop was replaced by $30 \mu \mathrm{L} 1.2 \mathrm{~g} / \mathrm{mL}$ of PEG 4000. After $10 \mathrm{~min}$ of treatment, the collapse rate of appressorium in $\Delta C g E n d 3$ was significantly higher than that of the WT and $\Delta C g E n d 3 / E N D 3$ (Figure $2 \mathrm{E}, \mathrm{F})$. This result indicates that the turgor pressure in $\Delta C g E n d 3$ was significantly decreased, which further affected the penetration ability of appressoria.

\section{4. $\Delta C g$ End3 Loses the Ability of Cellophane Membrane Penetration}

Cellophane is a permeable membrane, which is widely used in the penetration test of pathogenic fungi [50-52]. To determine the penetration ability of $\Delta C g E n d 3$, the hyphal blocks from WT, $\triangle C g E n d 3$, and $\Delta C g E n d 3 / E N D 3$ were inoculated on the sterile cellophane membrane overlaid on PDA plates. Plates was cultured at $25^{\circ} \mathrm{C}$ for 2 days (Pre). At 2 dpi, the entire membrane with colony was removed, and the resulting plates were cultured at $25^{\circ} \mathrm{C}$ for 2 days (Post). The results show that the colonies of WT and $\triangle \mathrm{CgEnd3/END3}$ were developed on PDA plates after the removal of cellophane membrane, indicating that WT and $\Delta C g E n d 3 / E N D 3$ successfully penetrated the cellophane membrane, but $\Delta C g E n d 3$ did not (Figure 3). Prolonged incubation before the removal of the cellophane membrane also failed to observe the successful penetration of $\Delta C g E n d 3$ (data not shown). This result indicated that $\Delta C g E n d 3$ lost its cellophane membrane penetration ability.

A

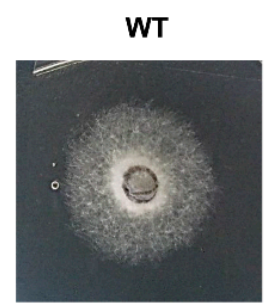

$\Delta$ CgEnd3-12

\section{$\Delta$ CgEnd3-36}
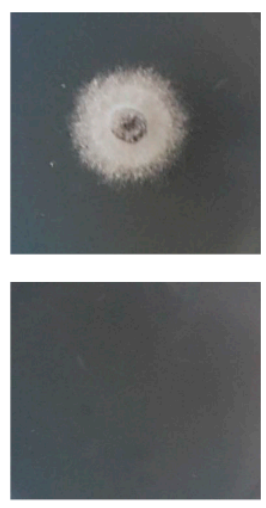
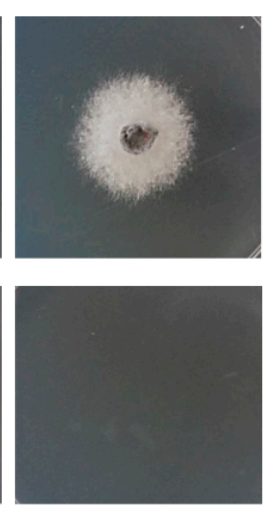

$\Delta$ CgEnd3/END3
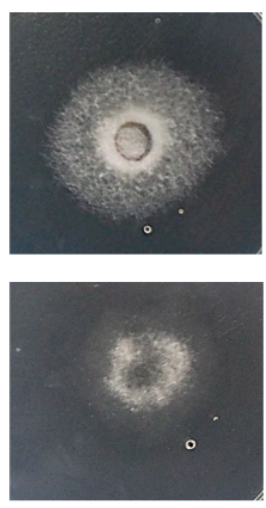

B

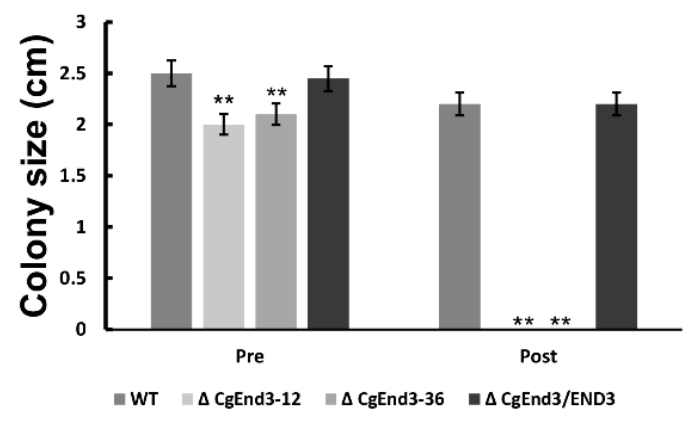

Figure 3. Cellophane membrane penetration assay. (A) Hyphal blocks from WT, $\triangle C g E n d 3$, and $\triangle C g E n d 3 / E N D 3$ were inoculated on cellophane membranes overlaid on PDA medium for 2 days at $25{ }^{\circ} \mathrm{C}$ (Pre). The cellophane membrane were removed, and the resulting plates were incubated at $25^{\circ} \mathrm{C}$ for 2 additional days (Post). This experiment was repeated three times. (B) Bar chart showing the colony size of each strain at 2 days post removal of cellophane membrane (Post). Error bars represent the standard deviations. Data were analyzed using Duncan's range test. Asterisks** indicate statistically significant differences at $p<0.05$. 


\subsection{CgEnd3 Is Involved in Oxidant Adaptation and the Regulation of Effectors during Early Infection Stage}

In plants, reactive oxygen species (ROS) plays a vital role in the defense against phytopathogens, and active oxygen bursts are among the earliest responses at the infection site [53]. Thus, oxidant adaptation is crucial for the successful infection of plant pathogenic fungi. To test the role of $C g E n d 3$ in the response to oxidative stress, the hyphal blocks of WT, $\triangle C g E n d 3$, and $\triangle C g E n d 3 / E N D 3$ were inoculated on PDA and PDA containing 5 or $10 \mathrm{mM}$ $\mathrm{H}_{2} \mathrm{O}_{2}$, respectively. At 4 dpi, the colony sizes of WT, $\Delta C g E n d 3$, and $\Delta C g E n d 3 / E N D 3$ were recorded, and the relative growth rate was calculated. The results show that the deletion of $C g E n d 3$ resulted in the defects in vegetative growth on PDA, but $\Delta C g E n d 3$ displayed resistance to oxidative stress compared with that of the WT and $\Delta C g E n d 3 / E N D 3$, especially when under the treatment of $10 \mathrm{mM} \mathrm{H}_{2} \mathrm{O}_{2}$ (Figure 4), suggesting that $C g E n d 3$ plays a negative role in oxidative stress response. To determine whether the deletion of $C g E n d 3$ affected the ROS adaptation during penetration, conidial suspensions $\left(10^{5}\right.$ conidia $\left./ \mathrm{mL}\right)$ from WT, $\Delta C g E n d 3$, and $\Delta C g E n d 3 / E N D 3$ were inoculated on the onion epidermal cell. At $9 \mathrm{hpi}$, water drops of each strain were replaced with $2 \mathrm{mg} / \mathrm{mL} 3,3^{\prime}$-diaminobenzidine (DAB) solution, and each sample was incubated in the dark for $12 \mathrm{~h}$. The results show that the ROS accumulated around the appressoria with dark brown polymers (Figure 5A), and the degree of staining for the appressorium of the $\triangle C g E n d 3$ was greater than that observed in WT and $\triangle C g E n d 3 /$ END3 (Figure $5 \mathrm{~A}, \mathrm{~B}$ ), indicating that the deletion of $C g E n d 3$ resulted in oxidant adaptation defects during penetration. To determine whether the stunted infection hyphae in $\triangle C g E n d 3$ was caused by the defect of oxidant adaptation during penetration, the ROS inhibitor, diphenyleneiodonium (DPI), was added during conidial germination at a final concentration of $5 \mu \mathrm{M}$, and the result shows that the stunted infection hyphae in $\triangle C g E n d 3$ was successfully rescued by exogenously added DPI (Figure 5C,D). These results indicate that $C g E n d 3$ is responsible for oxidant adaptation during penetration, which affects invasive growth.

A

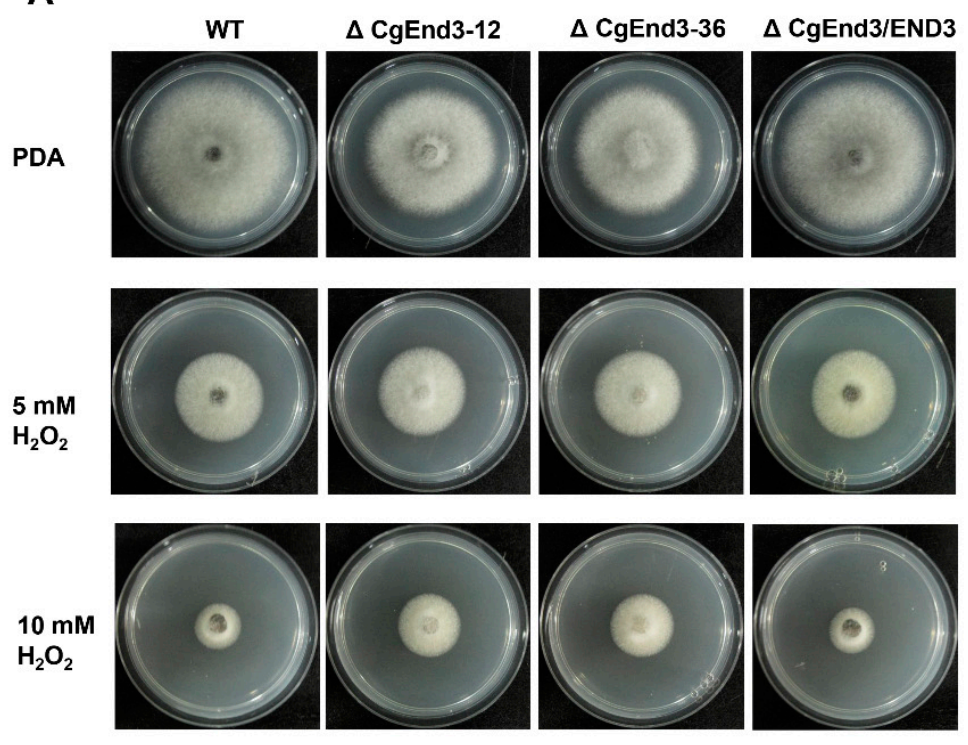

B
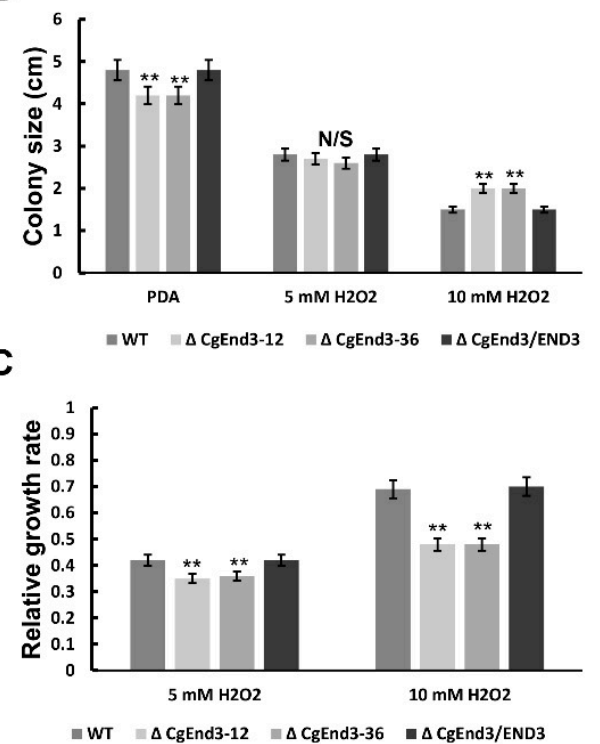

Figure 4. Vegetative growth under oxidative stress. (A) Hyphal block from WT, $\Delta C g E n d 3$, and $\Delta C g E n d 3 / E N D 3$ were inoculated on PDA or PDA mixed with 5 and $10 \mathrm{mM} \mathrm{H}_{2} \mathrm{O}_{2}$, respectively. Images were pictured at 4 dpi. This experiment was repeated three times. (B) Bar chart showing the colony size of each strain on PDA and PDA mixed with 5 and $10 \mathrm{mM} \mathrm{H}_{2} \mathrm{O}_{2}$. Error bars represent the standard deviations. Data were analyzed using Duncan's range test. Asterisks ** indicate statistically significant differences at $p<0.05$. N/S = difference not significant. (C) Bar chart showing the relative growth rate of each strain on PDA mixed with 5 and $10 \mathrm{mM} \mathrm{H}_{2} \mathrm{O}_{2}$; computing methods of relative growth rate were described by Wang et al. [54]. The deceased relative growth rate indicates the increased resistance to stress and vice versa. Error bars represent the standard deviations. Data were analyzed using Duncan's range test. Asterisks ** indicate statistically significant differences at $p<0.05$. 


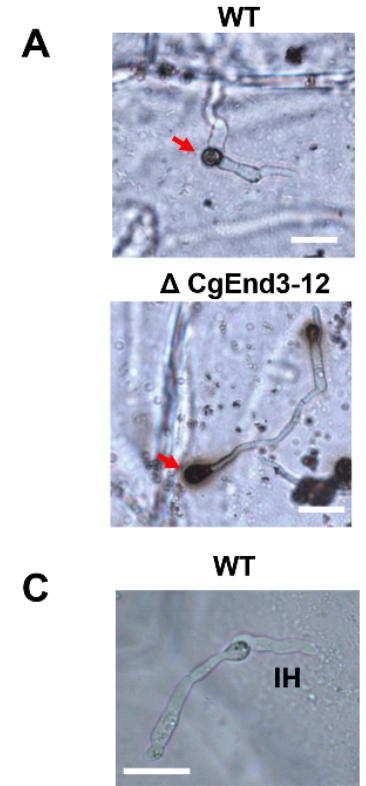

$\Delta$ CgEnd3

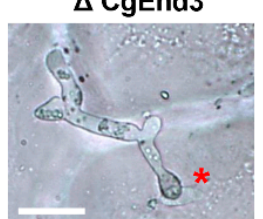

$\Delta$ CgEnd3/END3

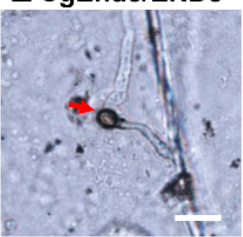

$\Delta$ CgEnd3-36

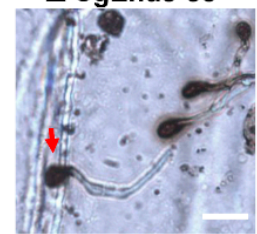

WT+5 $\mu \mathrm{M}$ DPI
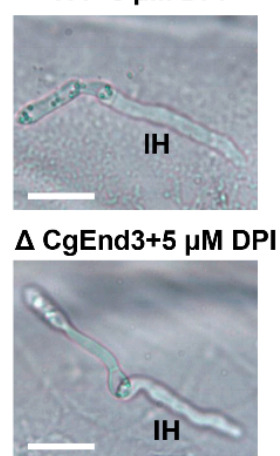

B

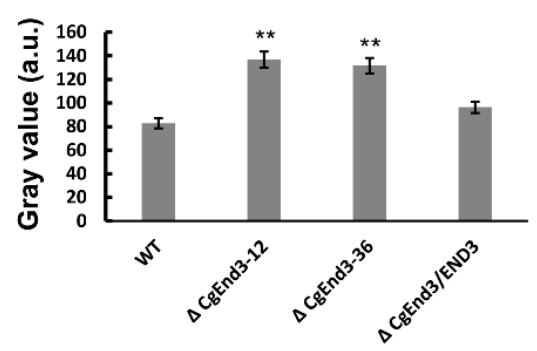

D

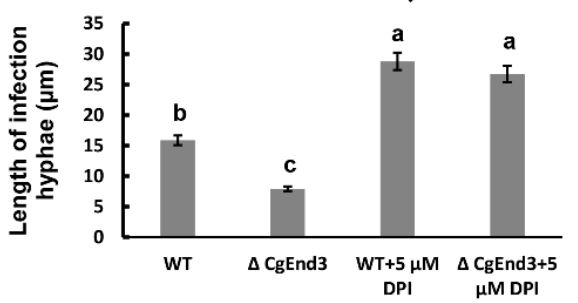

E

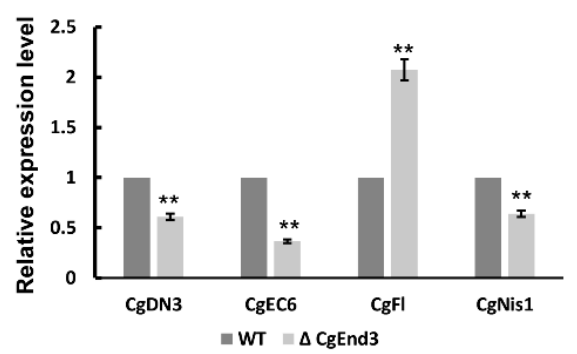

Figure 5. $\mathrm{CgEnd3}$ is involved in oxidant adaptation and expression of core effectors during the penetration of appressorium. (A) Equal volumes $(30 \mu \mathrm{L})$ of conidial suspensions $\left(10^{5}\right.$ conidia $\left./ \mathrm{mL}\right)$ from WT, $\Delta C g E n d 3$, and $\Delta C g E n d 3 / E N D 3$ were inoculated on the hydrophobic side of onion epidermal

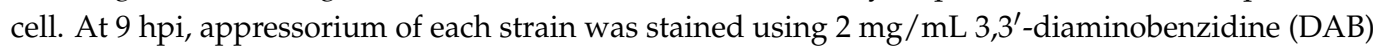
solution in darkness for $12 \mathrm{~h}$. Red arrow indicates the dark brown polymers in the presence of reactive oxygen species (ROS). This experiment was repeated three times. Bars $=10 \mu \mathrm{m}$. (B) The deposition of dark brown polymers was analyzed using ImageJ software, bar chart showing the gray value (a. u.) of each strain. Data were collected from at least 10 samples from each strain. Error bars represent the standard deviations. Data were analyzed using Duncan's range test. Asterisks ** indicate statistically significant differences at $p<0.05$. (C) Conidial suspensions $\left(10^{5}\right.$ conidia $\left./ \mathrm{mL}\right)$ from WT and $\Delta C g E n d 3$ were added with diphenyleneiodonium (DPI) at a final concentration of $5 \mu \mathrm{M}$. Images were photographed at 9 hpi. Red asterisk indicates the stunted infection hyphae. $\mathrm{IH}=$ infection hyphae. Bars $=10 \mu \mathrm{m}$. (D) Bar chart showing the mean length of infection hyphae from each sample. Data were collected from at least 20 infection hyphae, and this experiment was repeated three times. Error bars represent the standard deviations. The values indicated by the different letters are significantly different at $p<0.05$, as determined using post hoc Tukey's test. (E) Conidial suspensions $\left(10^{6}\right.$ conidia $\left./ \mathrm{mL}\right)$ from WT and $\Delta C g E n d 3$ were inoculated on poplar leaves. Inoculation areas (including fungal tissue and leaf tissue) were cut at $3 \mathrm{dpi}$, and $5 \mathrm{mg}$ samples from WT and $\triangle C g E n d 3$ areas were collected. Bar chart showing the expression of conserved effectors in WT and $\Delta C g E n d 3$ during early stage of infection. This experiment was repeated three times. Error bars represent the standard deviations. Data were analyzed using Duncan's range test. Asterisks ** indicate statistically significant differences at $p<0.05$.

Fungal effectors are secreted by phytopathogens to manipulate plant immunity. Moreover, certain effectors are conserved among different pathogens and regarded as core effectors; therefore, they may play an important and common role in pathogen virulence. In this study, the deletion of $\mathrm{CgEnd} 3$ resulted in severe defects in penetration, invasive growth, and oxidant adaptation, which indicates that the mutant is defective in host immune suppression and may be connected to the expression of core effectors. In this study, we identified effector genes or effector candidates that are homologous to other 
Colletotrichum species and suppress host immunity and facilitate invasive growth during the early infection stage, including CgDN3 (protein ID: 1717571) in C. gloeosporioides [55]; CgEC6 (protein ID: 1730105), which shares homology (82.1\%) to C. higginsianum ChEC6 [56]; $\mathrm{CgFl}$ (protein ID: 1731882), which shares homology (82.3\%) to Colletotrichum graminicola CgFl [57]; and CgNis1 (protein ID: 31327), which shares homology (68.5\%) to C. orbiculare CoNis1 [58]. In addition, our team previously performed a histopathology study of poplar leaves infected by C. gloeosporioides, and the results showed that the infection peg formed at the base of the appressorium expanded to form an infection vesicle after penetrating the host cuticle and epidermal cell wall at 3 dpi [6]. Therefore, the total RNA of the WT and $\Delta C g E n d 3$ during the early infection stage on poplar leaves at $3 \mathrm{dpi}$ were extracted, and qRT showed that the expression level of $C g D N 3, C g E C 6$, and $C g N i s 1$ were significantly decreased in $\triangle \mathrm{CgEnd} 3$, and the expression of $\mathrm{CgFl}$ was significantly upregulated in $\Delta C g E n d 3$ compared with that of the WT (Figure 5E). This result indicates that is $C g E n d 3$ involved in the regulation of core effectors during the early infection stage. Collectively, these results show that a lack of $C g E n d 3$ resulted in decreased ability in the suppression of host immunity.

\subsection{CgEnd3 Is Required for the Full Virulence}

In C. gloeosporioides, there are strong correlations between appressoria and pathogenicity. Additionally, it is clear that a lack of $C g E n d 3$ resulted in pleiotropic defects in appressorium formation, penetration, invasive growth, oxidant adaptation, and the expression of core effectors. Therefore, we further determined the role of $\mathrm{CgEnd} 3$ in the pathogenicity of C. gloeosporioides. Equal volumes $(30 \mu \mathrm{L})$ of conidial suspensions $\left(2 \times 10^{5}\right.$ conidia $\left./ \mathrm{mL}\right)$ from WT, $\Delta C g E n d 3$, and $\Delta C g E n d 3 / E N D 3$ were inoculated on poplar leaves. At $4 \mathrm{dpi}$, necrotic lesions appeared in the inoculation area of WT and $\Delta C g E n d 3 / E N D 3$, and the lesions gradually expanded between 4 and $8 \mathrm{dpi}$. However, no necrotic lesions were shown in $\triangle C g E n d 3$ at 4-7 dpi (Figure $6 \mathrm{~A}$ ). Since the $\Delta C g E n d 3$ was able to form appressoria on the Gel-bond membrane and onion epidermal cell, we presumed that the $\Delta C g E n d 3$ may retain weak pathogenicity, and prolonged observation ( $8 \mathrm{dpi}$ ) demonstrated that the pathogenicity in $\triangle C g E n d 3$ was significantly decreased but not fully abrogated (Figure $6 \mathrm{~A}, \mathrm{~B}$ ). These results indicate that $C g E n d 3$ was required for full virulence, and the significantly reduced virulence of $\triangle C g E n d 3$ was caused by the decreased ability of appressorium formation, penetration, and invasive growth, which is also attributed to decreased ability in suppressing host immunity.
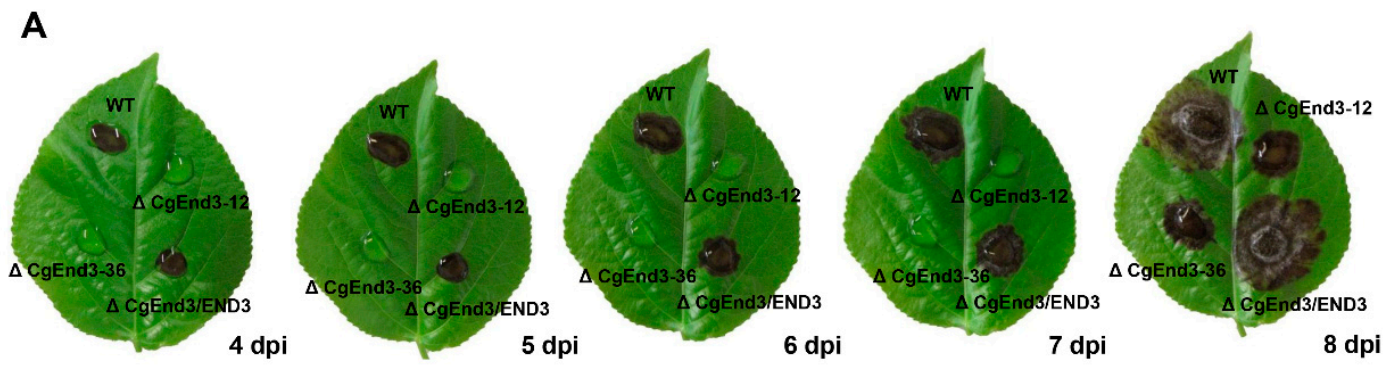

B

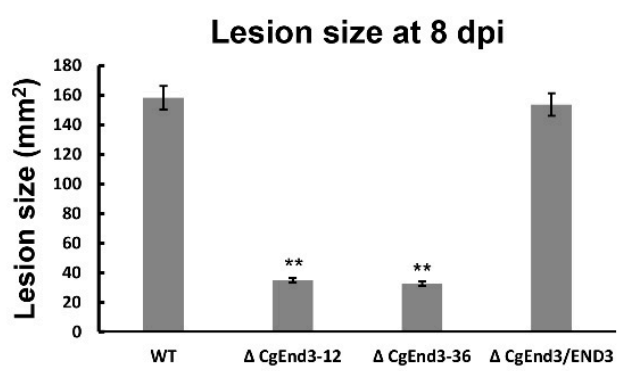

Figure 6. Pathogenicity assay on poplar leaves. (A) Equal volumes $(30 \mu \mathrm{L})$ of conidial suspensions $\left(2 \times 10^{5} \mathrm{conidia} / \mathrm{mL}\right)$ from WT, $\Delta C g E n d 3$, and $\Delta C g E n d 3 / E N D 3$ were inoculated on poplar leaves. Then, leaves were cultured at $25^{\circ} \mathrm{C}$ under moist 
environment. Images were pictured at 4-8 dpi. This experiment was repeated three times. (B) Bar chart showing the lesion sizes of WT, $\Delta C g E n d 3$, and $\Delta C g E n d 3 / E N D 3$ at $8 \mathrm{dpi}$. Error bars represent the standard deviations. Data were analyzed using Duncan's range test. Asterisks ${ }^{* *}$ indicate statistically significant differences at $p<0.05$.

\subsection{CgEnd3 Involved in the Calcium Signaling in C. gloeosporioides}

CgEnd3 encodes a predicted 397 amino acid protein and contains four calcium ionbinding sites (Figure S1A), indicating that CgEnd3 may have a role in calcium signaling. To determine whether $\mathrm{CgEnd} 3$ is involved in calcium signaling, hyphal blocks from WT, $\triangle C g E n d 3$, and $\triangle C g E n d 3 / E N D 3$ were inoculated on the Yeast extract-glucose medium (YEG) and YEG containing $0.4 \mathrm{M}$ and $0.6 \mathrm{M} \mathrm{Ca}^{2+}$, respectively. The results show that the deletion of $C g E n d 3$ also caused defects in vegetative growth on YEG and significantly increased the resistance to $0.6 \mathrm{M} \mathrm{Ca}^{2+}$ stress (Figure $7 \mathrm{~A}-\mathrm{C}$ ), indicating that $C g E n d 3$ plays a negative role in the response to $\mathrm{Ca}^{2+}$ stress. To further illuminate the role of $\mathrm{CgEnd3}$ in calcium signaling, the transcription level of various calcium signaling genes, including calcineurin-responsive zinc finger transcription factor CgCrz1 (protein ID: 1748597), calmodulin CgCam1 (protein ID: 1748141), calcium transporting ATPase CgPmc1 (protein ID: 1729318), $\mathrm{Ca}^{2+}$ sensor CgNcs1 (protein ID: 50723), and $\mathrm{Ca}^{2+} /$ calmodulin-dependent protein kinase CgCamk1 (protein ID: 1743859), were tested using qRT-PCR analysis. The results show that the deletion of $C g E n d 3$ leads to significantly increased transcription levels of $C g C r z 1, C g C a m 1$, CgNcs1, and CgCamk1, but it decreased the transcription level of CgPmc1 (Figure 7D). Interestingly, $\mathrm{CgCam1}, \mathrm{CgNcs} 1, \mathrm{CgCamk1}$, and $\mathrm{CgEnd} 3$ all possess the $\mathrm{EF}$ hand domain or belong to the EF hand protein superfamily, and previous studies have revealed that the EF hand protein superfamily is composed of a large number of functionally diverse $\mathrm{Ca}^{2+}$ binding proteins, and they play vital roles in $\mathrm{Ca}^{2+}$ homeostasis and $\mathrm{Ca}^{2+}$ signaling mechanisms [59,60], indicating that $C g E n d 3$ may have a negative regulation toward the transcription of the EF hand superfamily. Additionally, there exists the possibility that the upregulated expression of $\mathrm{EF}$ hand proteins was caused by a genetic compensation due to the deletion of $C g E n d 3$. Collectively, these results suggested that $C g E n d 3$ plays an important role in calcium signaling in C. gloeosporioides.
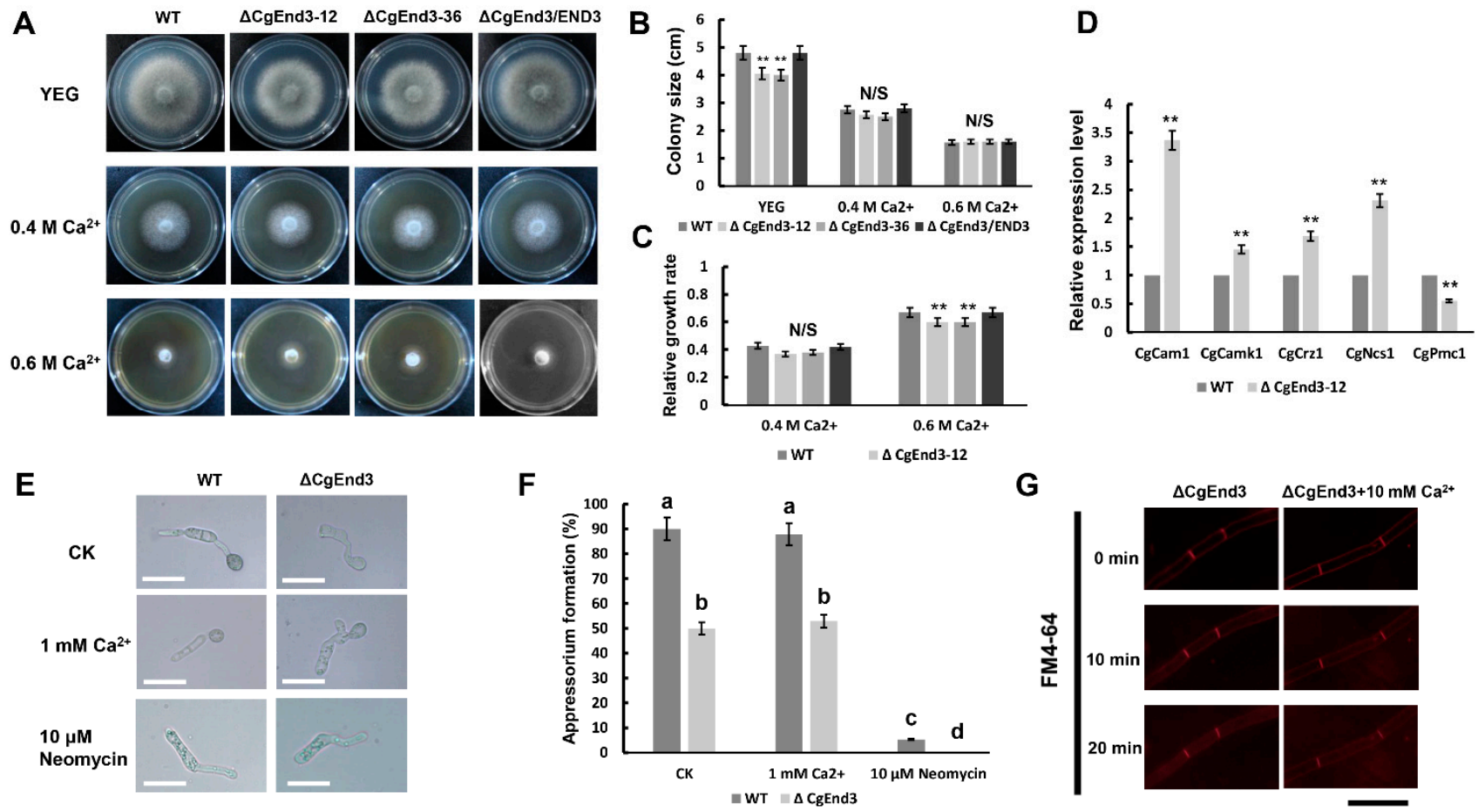

Figure 7. Role of $\mathrm{CgEnd} 3$ in calcium signaling. (A) Hyphal block from WT, $\triangle \mathrm{Cg} E n d 3$, and $\triangle \mathrm{CgEnd3/END3}$ were inoculated on Yeast extract-glucose medium (YEG) and YEG containing 0.4 and $0.6 \mathrm{M} \mathrm{Ca}^{2+}$, respectively. Strains were cultured at $25^{\circ} \mathrm{C}$ 
for 4 days. This experiment was repeated three times. (B) Bar chart showing the colony size of each strain on YEG and YEG containing 0.4 and $0.6 \mathrm{M} \mathrm{Ca}^{2+}$ in (A). Data were analyzed using Duncan's range test. Asterisks ${ }^{* *}$ indicate statistically significant differences at $p<0.05$. N/S = difference not significant. (C) Bar chart showing the relative growth rate of each strain under the treatment of 0.4 and $0.6 \mathrm{M} \mathrm{Ca}^{2+}$. Error bars represent the standard deviations. Data were analyzed using Duncan's range test. Asterisks ** indicate statistically significant differences at $p<0.05 . \mathrm{N} / \mathrm{S}=$ difference not significant. (D) Bar chart showing the relative expression of five calcium signaling genes in WT and $\Delta C g E n d 3$. This experiment was repeated three times. Error bars represent the standard deviations. Data were analyzed using Duncan's range test. Asterisks ${ }^{* *}$ indicate statistically significant differences at $p<0.05$. (E) The effects of exogenous $1 \mathrm{mM} \mathrm{Ca}^{2+}$ and $10 \mu \mathrm{M}$ of the phospholipase $\mathrm{C}$ inhibitor neomycin on appressorium formation in WT and $\Delta C g E n d 3$ at $9 \mathrm{hpi}$. This experiment was repeated three times. Bars $=10 \mu \mathrm{m}$. (F) Bar chart showing the rate of appressorium formation under the treatment of $1 \mathrm{mM} \mathrm{Ca}^{2+}$ or $10 \mu \mathrm{M}$ neomycin. Error bars represent the standard deviations. The values indicated by the different letters are significantly different at $p<0.05$, as determined using post hoc Tukey's test. (G) The internalization of FM4-64 in $\Delta C g E n d 3$ in the presence of $10 \mathrm{mM} \mathrm{Ca}^{2+}$. Images were photographed at different time points $(0-20 \mathrm{~min})$ using fluorescence microscope. Bars $=10 \mu \mathrm{m}$. This experiment was repeated three times.

Calcium signaling has a conserved function in the regulation of appressorium formation in M. oryzae [61], and calcium channel blockers specifically reduced appressorium formation in C. gloeosporioides [62]. Therefore, we firstly tested the effect of calcium signaling inhibitor neomycin in C. gloeosporioides, and we found that the exogenous supplement of neomycin specifically inhibited appressorium formation in WT and $\triangle \mathrm{CgEnd} 3$ without affecting conidial germination (Figure 7E,F). This proved that calcium signaling is involved in the regulation of appressorium formation in C. gloeosporioides. To determine whether the defect of appressorium formation in $\triangle C g E n d 3$ has a connection with its role in calcium signaling, the effect of the exogenous addition of $\mathrm{Ca}^{2+}$ on appressorium formation was tested. This demonstrated that the exogenous addition of $1 \mathrm{mM} \mathrm{Ca}^{2+}$ failed to rescue the defects of appressorium formation in $\Delta C g E n d 3$ (Figure 7E,F). Other concentrations of exogenous $\mathrm{Ca}^{2+}$ also demonstrated no replenishment effect (data not shown). In addition, another core function of $\mathrm{CgEnd3}$ is to regulate normal endocytosis. Therefore, we intended to explore whether the endocytosis regulated by $C g E n d 3$ is related to the calcium signal, and the results show that exogenous $\mathrm{Ca}^{2+}$ also failed to rescue the endocytosis defect in $\Delta C g E n d 3$ (Figure 7G). Collectively, these results indicated that $C g E n d 3$ regulated appressorium formation and endocytosis in a calcium signaling-independent manner.

\subsection{CgEnd3 Is Required for Cell Wall Integrity}

Calcium signaling has a conserved connection with cell-wall integrity (CWI) signaling in various fungi [34]. To determine the function of $C g E n d 3$ in abiotic stress response, hyphal blocks from WT, $\Delta C g E n d 3$, and $\Delta C g E n d 3 / E N D 3$ were inoculated on PDA containing $1.2 \mathrm{M} \mathrm{NaCl}, 1 \mathrm{M}$ sorbitol, and $120 \mu \mathrm{g} / \mathrm{mL}$ CFW, respectively. The results indicate that $\triangle C g E n d 3$ showed similar restriction rates in the presence of $1.2 \mathrm{M} \mathrm{NaCl}$ and $1 \mathrm{M}$ sorbitol, compared with those of the WT and $\triangle C g E n d 3 / E N D 3$ (Figure 8A-C), indicating that $C g E n d 3$ was dispensable for the response to osmotic stress. However, $\Delta C g E n d 3$ showed resistance to $120 \mu \mathrm{g} / \mathrm{mL}$ cell wall integrity agent CFW compared with that of the WT and $\Delta C g E n d 3 /$ END3 (Figure 8A-C). This result indicated that $C g E n d 3$ plays a role in cell-wall integrity. The cell wall of filamentous fungi is the place of first contact with external stresses and is mainly composed of chitin [63]. S. cerevisiae End3p is required for the correct distribution of chitin at the cell surface [47]. In this study, CFW staining was used to investigate the deposition of chitin in hyphae. Hyphae from each strain were stained using $1 \mu \mathrm{g} / \mathrm{mL}$ CFW for 3 min under darkness. In WT, chitin was mainly located in the septum and hyphal tip, and it was equally distributed on the cell wall. In contrast, chitin at septum in $\Delta C g E n d 3$ was dispersed, which represents fragmentary septum. In addition, chitin was deposited in a punctiform pattern at the hyphal tips (Figure 8D,E). In filamentous fungi, the chitin synthase was reported to be responsible for the synthesis of chitin [64]. In S. cerevisiae [65], Metarhizium acridum [66], Fusarium graminearum [67], and B. cinerea [68] chitin synthase are required for cell-wall integrity. In this study, we identified 
seven chitin synthases CgChs1-CgChs7 (Protein IDs: 1900258, 361644, 1836492, 1744167, 1830816, 1462050, and 30251, respectively) in C. gloeosporioides, and qRT-PCR was applied to determine the relative expression levels of these genes in WT and $\Delta C g E n d 3$. The results show that the transcription levels of CgChs1, CgChs3, CgChs4, CgChs5, and CgChs6 were significantly increased in $\Delta C g E n d 3$ compared with those of the WT, while CgChs2 and $\mathrm{CgChs} 7$ were significantly decreased (Figure $8 \mathrm{~F}$ ). These results indicate that $\mathrm{CgEnd} 3$ plays an important role in the cell-wall integrity of $C$. gloeosporioides.

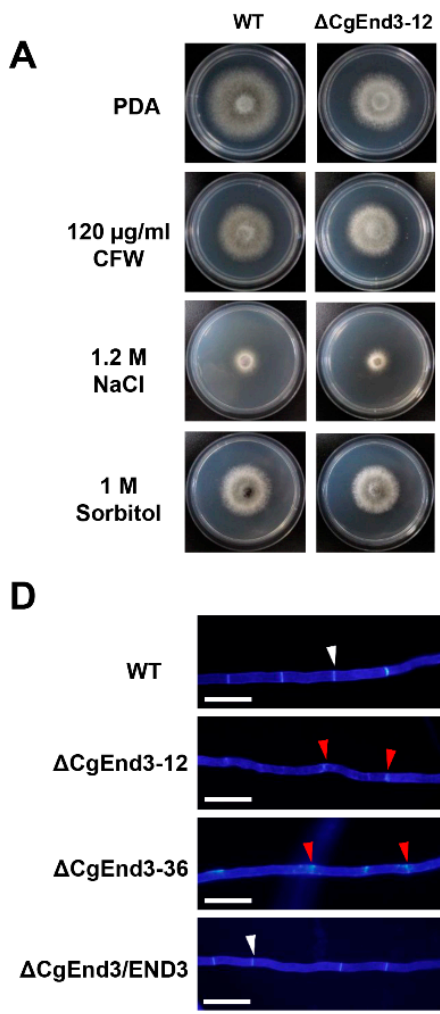

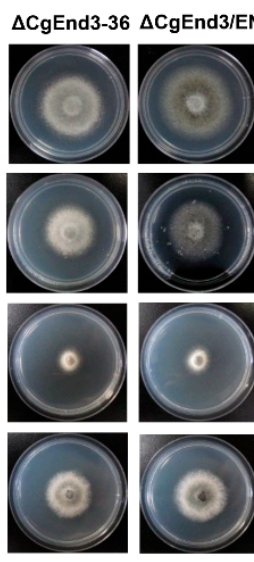

E

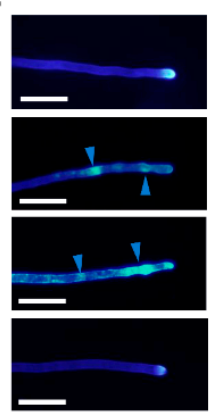

B

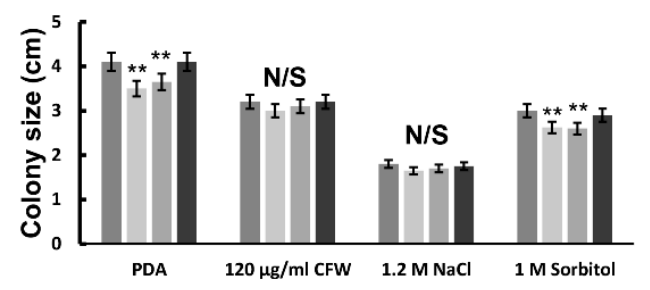

C $\because W T=\Delta$ CgEnd3-12 $\backsim \Delta$ CgEnd3-36 $=\Delta$ CgEnd3/END3

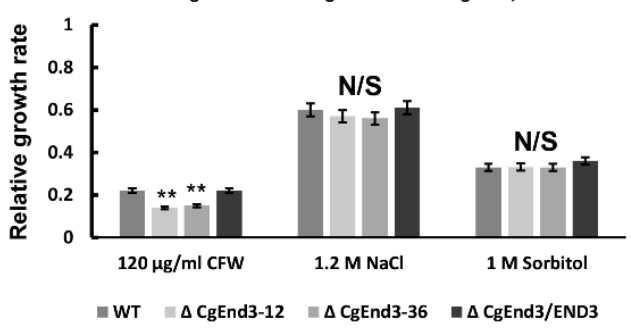

$\mathbf{F}$

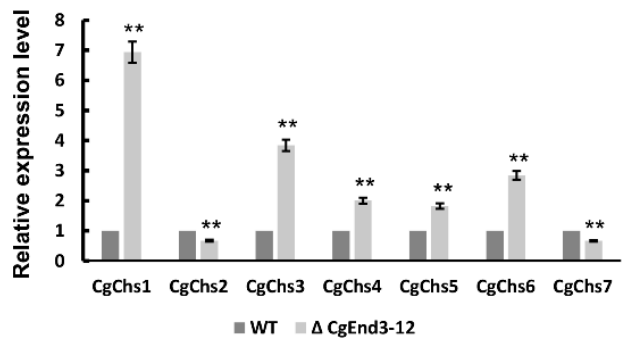

Figure 8. Response to cell wall integrity agents and high osmotic stress, calcofluor white (CFW) staining of hyphae and relative expression of seven chitin synthase genes. (A) Vegetative growth of WT, $\triangle C g E n d 3$, and $\triangle C g E n d 3 / E N D 3$ on PDA and PDA containing $120 \mu \mathrm{g} / \mathrm{mL} \mathrm{CFW,} 1.2 \mathrm{M} \mathrm{NaCl}$, and $1 \mathrm{M}$ sorbitol, respectively. Strains were cultured at $25^{\circ} \mathrm{C}$ for 4 days. This experiment was repeated three times. (B) Bar chart showing the colony size of each strain in (A). Error bars represent the standard deviations. Data were analyzed using Duncan's range test. Asterisks ** indicate statistically significant differences at $p<0.05$. N/S = difference not significant. (C) Bar chart showing the relative growth rate of each strain in the presence of $120 \mu \mathrm{g} / \mathrm{mL} \mathrm{CFW,} 1.2 \mathrm{M} \mathrm{NaCl}$, and $1 \mathrm{M}$ sorbitol, respectively. Error bars represent the standard deviations. Data were analyzed using Duncan's range test. Asterisks ** indicate statistically significant differences at $p<0.05$. N/S $=$ difference not significant. (D) CFW staining of hyphal septa from WT, $\Delta C g E n d 3$, and $\Delta C g E n d 3 / E N D 3$. White arrow indicates the intact septum in WT. Red arrow indicates the dispersed chitin at septum. Bars $=10 \mu \mathrm{m}$. (E) CFW staining of hyphal tip from WT, $\Delta C g E n d 3$, and $\Delta C g E n d 3 / E N D 3$. Blue arrow indicates the punctiform pattern of chitin distribution at the hyphal tips. This experiment was repeated three times. Bars $=10 \mu \mathrm{m}$. (F) Bar chart showing the relative expression level of seven chitin synthase genes in WT and $\Delta C g E n d 3$. This experiment was repeated three times. Data were analyzed using Duncan's range test. Asterisks ${ }^{* *}$ indicate statistically significant differences at $p<0.05$.

\subsection{Lack of CgEnd3 Resulted in Increased Resistance to Fungicide Fludioxonil}

Previous studies also illustrated a connection between calcium signaling and drug resistance in pathogenic fungus [69]. To determine the role of CgEnd3 in response to antifungal drugs, two types of broad-spectrum fungicides of anthracnose, difenoconazole and fludioxonil [70], were tested. Hyphal blocks from WT, $\Delta C g E n d 3$, and $\Delta C g E n d 3 / E N D 3$ were inoculated on PDA containing $0.8 \mu \mathrm{g} / \mathrm{mL}$ difenoconazole and 5 and $10 \mu \mathrm{g} / \mathrm{mL}$ fludioxonil, respectively. At $4 \mathrm{dpi}$, each strain was significantly suppressed, but the relative 
growth rate of $\triangle C g E n d 3$ was similar with that of the WT under the treatment of $0.8 \mu \mathrm{g} / \mathrm{mL}$ difenoconazole. However, $\Delta C g E n d 3$ showed significantly increased resistance to 5 and $10 \mu \mathrm{g} / \mathrm{mL}$ fludioxonil compared with that of the WT (Figure 9). This result showed that $\mathrm{CgEnd3}$ plays a negative role in the resistance to fludioxonil.

A

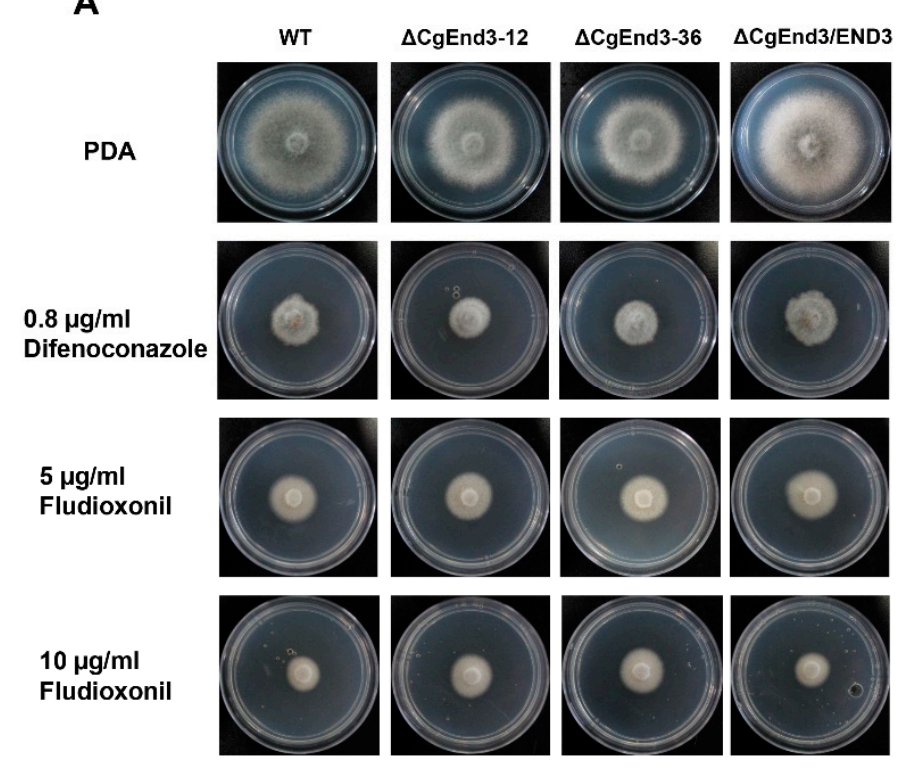

B

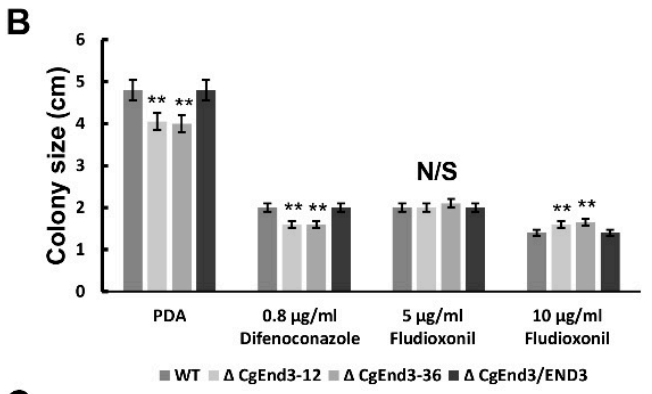

C

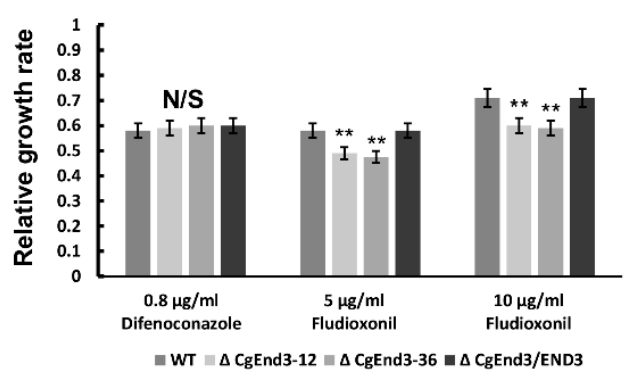

Figure 9. Response to the fungicide fludioxonil. (A) Vegetative growth of WT, $\Delta C g E n d 3$, and $\Delta C g E n d 3 / E N D 3$ on PDA and PDA containing $0.8 \mu \mathrm{g} / \mathrm{mL}$ difenoconazole, 5 and $10 \mu \mathrm{g} / \mathrm{mL}$ fludioxonil, respectively. Strains were cultured at $25^{\circ} \mathrm{C}$ for 4 days. This experiment was repeated three times. (B) Bar chart showing the colony size of each strain in (A). Data were analyzed using Duncan's range test. Asterisks ** indicate statistically significant differences at $p<0.05$. N/S = difference not significant. (C) Bar chart showing the relative growth rate of each strain on PDA containing $0.8 \mu \mathrm{g} / \mathrm{mL}$ difenoconazole, 5 and $10 \mu \mathrm{g} / \mathrm{mL}$ fludioxonil, respectively. Data were analyzed using Duncan's range test. Asterisks ${ }^{* *}$ indicate statistically significant differences at $p<0.05 . \mathrm{N} / \mathrm{S}=$ difference not significant.

\section{Discussion}

In this study, we characterized the $\mathrm{CgEnd} 3$ homologous to the $\mathrm{EH}$ domain-containing protein End3p of S. cerevisiae. In S. cerevisiae, End3p cooperated with another EH domaincontaining protein Pan1p to regulate the cortical actin cytoskeleton and endocytosis [45]. Further study revealed that Pan1p and End3p mixes interact with another protein, Sla1p, which is also known to be required for the assembly of cortical actin. The Pan1p-End3pSla1p complex is required for actin cytoskeleton and cell-wall morphogenesis [71], and it links Arp2/3-mediated actin assembly to sites of clathrin-mediated endocytosis [46]. These studies indicated that End3p plays important roles in the actin cytoskeleton, cell wall morphogenesis, and endocytosis. In M. oryzae, MoEnd3 plays an important role in endocytosis, and the deletion of MoEnd3 affected appressorium formation and pathogenicity [72]. In this study, the deletion of $C g E n d 3$ also resulted in defects of endocytosis, indicating that End3 may act as a conserved regulator of endocytosis in fungi. Moreover, a lack of $C g E n d 3$ resulted in decreased vegetative growth and deficient polarity during germination. In previous studies, it was found that filamentous fungi are able to spread to the hyphae at a speed of $18.5 \mu \mathrm{m} / \mathrm{min}$, and the rapid spreading of hyphae requires normal endocytosis [73]. Both exo- and endocytosis were reported to be involved in polarized growth in $U$. maydis and S. cerevisiae $[74,75]$. Therefore, $\mathrm{CgEnd} 3$ may regulate vegetative growth and polarity in an endocytosis-dependent way. Aside from the perspectives of growth and polarity, $\mathrm{CgEnd} 3$ also acts as a key regulator in pathogenicity-related functions, including appressorium formation, appressorium melanization, turgor pressure, penetration, and invasive growth. The occurrence of these phenotypes is valid, because endocytosis is 
the basic physiological process of cells, pleiotropic defects will occur when endocytosis is blocked, and endocytosis is required for appressorium formation in C. gloeosporioides (Figure 1C,D). In any case, the underlying connection between endocytosis and appressorium formation was supported by the study of MoEnd3, since the deletion of MoEnd3 showed severe defects in endocytosis and the endocytosis-mediated internalization of cell membrane sensors, MoSho1 and MoPth11 [72]. In many fungi, Sho1 and Pth11 were reported as upstream sensors in the Pmk1 mitogen-activated protein (MAP) kinases (MAPK) and cAMP pathways to regulate host signal recognition and appressorium formation, respectively [9-11,76]. Therefore, the defects of appressorium formation in $\Delta C g E n d 3$ may be due to the defects in endocytosis-mediated internalization of cell membrane sensors in C. gloeosporioides. Further experiments are needed to illuminate the underlying mechanisms of endocytosis-dependent appressorium formation.

In fungi, the cell wall protects cells from the harm of environmental stresses, including temperature, $\mathrm{pH}$, and lysing enzyme. CWI signaling plays an important role in maintaining the morphology and functions of the cell wall, and the CWI pathway helps fungi to reinforce the cell wall [77]. In S. cerevisiae, the molecular mechanism of CWI is well understood. There are five mitogen-activated protein (MAP) kinase pathways in yeast, and the Slt2 MAP kinase pathway plays a central role in CWI. The Slt2 MAP kinases consist of MAPKKK Bck1, MAPKK Mkk1, and MAPK Slt2, and there are several downstream transcription factors, including Swi4, Swi6, and Rlm1, which are also involved in the regulation of CWI $[77,78]$. In filamentous fungi, several genes that are required for CWI have also been identified. In M. oryzae, the deletion of Mps1 (Slt2 ortholog) resulted in defects in aerial hyphae growth and conidiation, appressorium penetration, and pathogenicity $[79,80]$. In C. gloeosporioides, the deletion of $\mathrm{CgSlt} 2$ resulted in the defects in appressorium formation, sporulation, polarized growth, and pathogenicity. However, the function of CgSlt2 in CWI is not yet clear, but the spores harvested from the $\mathrm{CgSlt} 2$ mutant cultured on medium mixed with sorbitol developed small and nonmelanized appressorium-like structures [81]. In addition, two small $\mathrm{G}$ proteins, $\mathrm{CgRhoB}$ and $\mathrm{CgCdc} 42$, are involved in $\mathrm{CWI}$, and their deletion affected the responses to cell-wall stress agents and protoplast release. In any case, $\Delta C g R h o B$ and $\Delta C g C d c 42$ showed an abnormal distribution of chitin in hyphae, and $\mathrm{CgCdc42}$ is involved in the regulation of chitin synthase genes [3,54]. The putative upstream cell surface sensor, CgSho1, also plays an important role in cell-wall integrity [82]. In this study, the deletion of $\mathrm{CgEnd} 3$ affected the transcription of chitin synthase genes $\mathrm{CgChs1-}$ $\mathrm{CgChs} 7$, and it affected the response to the cell-wall integrity stress agent. Additionally, the chitin distribution at the septum and hyphal tip was also changed, compared to that of the WT. These results indicated that $C g E n d 3$ plays an important role in CWI. Moreover, $\mathrm{CgEnd} 3$ contains four calcium ion binding sites, and it is involved in calcium signaling in C. gloeosporioides. Previous reports reveal that calcineurin plays an important role in the virulence pathways of eukaryotic microbial pathogens, including invasive growth, drug tolerance, and CWI. In Sclerotinia sclerotiorum, calcineurin signaling is involved in CWI [34]. In $V$. dahliae, the deletion of calcineurin-responsive zinc finger transcription factor $V d C r z 1$ showed hypersensitivity to the cell-wall perturbing agent, SDS [36]. In B. cinerea, the deletion of $B c C r z 1$ also caused defects in CWI [37]. In M. oryzae, phospholipase C (PLC) acts as a $\mathrm{Ca}^{2+}$ supplier by generating $\mathrm{Ca}^{2+}$-releasing molecules, and two phospholipase $\mathrm{C}$ genes, MoPlc2 and MoPlc3, were involved in CWI. The deletion of MoPlc2 and MoPlc3 affected the response to CWI stress agent CFW and showed hypersensitivity to the lysing enzyme [83]. In Candida albicans, $\mathrm{Ca}^{2+} / \mathrm{H}^{+}$antiporter GaGdt1 and calcium pump CaPmr1 have cooperative roles in CWI [84]. Collectively, those studies indicated that calcium signaling possesses a conserved connection with CWI, and the involvement of $C g E n d 3$ in calcium signaling may further affect CWI in C. gloeosporioides.

In this study, the deletion of $C g E n d 3$ resulted in increased resistance to the cell wall stress agent $\mathrm{CFW}$, oxidative stress, calcium ion stress, and fungicide fludioxonil, indicating that $C g E n d 3$ acts as a negative regulator in response to multiple stresses. In C. gloeosporioides, the mitogen-activated protein kinase, $\mathrm{CgHog} 1$, is the central regulator for the resistance to 
fludioxonil, and the deletion of $\mathrm{CgHog} 1$ showed enhanced resistance to fludioxonil. In any case, the analysis of genome-wide transcription patterns in C. gloeosporioides showed that $\mathrm{Ca}^{2+}$-transporting ATPase was downregulated under the treatment of $10 \mu \mathrm{g} / \mathrm{mL}$ of fludioxonil, indicating the involvement of calcium signaling in drug resistance [70]. Previous reports also suggested that calcineurin is required for virulence and drug resistance in a diverse group of fungi, mainly in human fungal pathogens, including azole tolerance in $C$. albicans [85], fluconazole tolerance in Cryptococcus gattii [86], and azole and echinocandin resistance in Aspergillus fumigatus [87]. Therefore, it is intriguing to further identify the underlying mechanisms of the relationship between calcium signaling and drug resistance.

In C. gloeosporioides and other appressorium-forming fungi, there are strong connections between appressoria and virulence [5,52]. In this study, the deletion of $C g E n d 3$ showed pleiotropic defects in appressorium-related functions, including appressorium formation, appressorium melanization, turgor pressure, and penetration. In plants, ROS plays a crucial role in the defense against infections by pathogens, and oxidative bursts are among the earliest responses at the infection site [53]. Therefore, oxidant adaptation is also crucial for the infection of plant pathogenic fungi. In C. gloeosporioides, we previously revealed the significance of ROS tolerance to pathogenicity. The deletion of the zinc finger transcription factor gene, $C g A p 1$, leads to defects in ROS tolerance and reduced pathogenicity [4]. The small $\mathrm{G}$ protein $\mathrm{CgRhoB}$ is involved in oxidative stress response and ROS tolerance during penetration. The deletion of $C g R h o B$ resulted in reduced pathogenicity [3]. The deletion of another small $\mathrm{G}$ protein $\mathrm{CgCdc42}$ also showed defects in ROS tolerance, and it further impacted the pathogenicity. Moreover, the exogenous treatment of ROS inhibitor diphenyleneiodonium (DPI) rescued the pathogenicity of the $C g C d c 42$ deletion mutant [54]. These results showed that both appressorium- and ROS-related functions are vital factors in the pathogenicity of $C$. gloeosporioides. In this study, $C g E n d 3$ plays an important role in pathogenicity, and the reduced pathogenicity may be caused by the multiple defects of $\triangle C g E n d 3$ in appressorium formation and penetration-related functions. Intriguingly, the defect of invasive growth was rescued by the exogenous addition of DPI, and the transcription of core effectors was regulated by $C g E n d 3$ during the early infection stage. These results indicated the participation of $C g E n d 3$ in the suppression of host immunity. In addition, the penetration of the cellophane membrane was abolished in $\Delta C g E n d 3$, indicating that there are connections between the ability of penetration and pathogenicity. In other pathogenic fungi, including M. oryzae [88], F. oxysporum [89], V. dahliae [90], and Colletotrichum species [52], cellophane membrane penetration is an important indicator for their pathogenicity. However, no reports revealed the mechanism of the connection between the penetration of cellophane membrane and pathogenicity. Therefore, we observed the interface between cellophane membrane and PDA plates, but no obvious penetration structures or appressoria were formed at the interface (data not shown), indicating that C. gloeosporioides may penetrate the cellophane membrane through hyphae or unknown microstructure that are differentiated from hyphae.

Collectively, our study determined the key role of $C g E n d 3$ in regulating endocytosis and revealed the novel function of End3 in calcium signaling. Moreover, $\mathrm{CgEnd} 3$ plays important roles in appressorium formation, appressorium melanization, turgor pressure accumulation, penetration, invasive growth, expression of core effectors, and pathogenicity. The deletion of $C g E n d 3$ showed negative responses to the cell-wall integrity agent CFW, calcium ion stress, oxidative stress, and fungicide fludioxonil. Our results revealed the pleiotropic roles of $C g E n d 3$ in C. gloeosporioides and suggested that $C g E n d 3$ or endocytosisrelated genes function as promising antifungal targets.

\section{Materials and Methods}

\subsection{Cultivation of Fungi}

The Colletotrichum gloeosporioides sensu stricto (s.s.) CFCC80308 strain was isolated from the leaves of Populus $\times$ beijingensis with symptoms of anthracnose in Beijing Botanical Garden, conserved in the China Forestry Culture Collection Center (CFCC), and supplied 
by the Key Laboratory for Silviculture and Conservation of Ministry of Education, Beijing Forestry University (Beijing, China) was served as the WT throughout this study [2,3]. WT, and other derivative strains, were maintained on solid PDA medium at $25^{\circ} \mathrm{C}$. Liquid complete medium $(1 \mathrm{~L} \mathrm{CM}, 50 \mathrm{~mL} 20 \times$ nitrate salts, $1 \mathrm{~mL}$ vitamin solution, $1 \mathrm{~mL} 1000 \times$ Trace, $10 \mathrm{~g}$ glucose, $2 \mathrm{~g}$ peptone, $1 \mathrm{~g}$ yeast extract, $1 \mathrm{~g}$ casamino acids) was applied to generate the shaking culture of strains. For the selection of sulfonylurea resistant strains, TB3 medium (1 L TB3, 3 g yeast extract, $3 \mathrm{~g}$ casamino acids, $200 \mathrm{~g}$ sucrose, and $7 \mathrm{~g}$ agar) was used to screen the deletion mutants. For the fluorescence microscopy of CFW staining, conidial suspensions of each strain were inoculated on PDA-coated glass slides. The $\mathrm{Ca}^{2+}$-free YEG medium (1 L YEG, $5 \mathrm{~g}$ yeast extract, $10 \mathrm{~g}$ glucose and $7 \mathrm{~g}$ agar) was used to test the response to high calcium ion stress.

\subsection{Isolation and Phylogenetic Analysis of $\mathrm{CgEnd} 3$}

The sequence of CgEnd3 (Protein ID: 1451078) was obtained from the genome database of C. gloeosporioides (http:/ / genome.jgi.doe.gov/Gloci1/Gloci1.home.html) (accessed on 10 June 2019) using the BLASTP algorithm, based on the sequence of the S. cerevisiae End3p (NP_014315.1). The identification of CgEnd3 was based on the amino acid sequence homology to other fungi, including MoEnd3 in M. oryzae (MGG_06180), CoEnd3 in C. orbiculare (TDZ22908.1), CfEnd3 in Colletotrichum fructicola (XP_031885343.1), NcEnd3 in Neurospora crassa (XP_962381.2), FoEnd3 in Fusarium oxysporum (EXM25519.1), and End3p in S. cerevisiae (NP_014315.1) using ClustalX 2.1 (Figure S1A). The phylogenetic tree was constructed by MEGA 7.0 using full-length protein sequences and the neighbor-joining method with 1000 bootstrap replications (Figure S1B), as previously described [91]. The $\mathrm{EF}$ hand domain and calcium ion binding sites of CgEnd3 were predicted using the InterProScan tool (https: / / www.ebi.ac.uk/interpro) (accessed on 10 June 2019) [92].

\subsection{Generation of $\mathrm{CgEnd} 3$ Deletion Mutants}

The split-marker method [93] was used to construct targeted deletion cassettes containing the sulfonylurea (Sur) resistance gene to replace the native $\mathrm{CgEnd3}$ gene in $\mathrm{C}$. gloeosporioides (Figure S2A). The Sur resistance-conferring gene, carried by PCB1523 [94], was kindly provided by Prof. Richard Wilson, University of Nebraska-Lincoln. Firstly, to generate the fusion fragments, approximately $1.5 \mathrm{~kb}$ upstream and downstream flanking sequences were amplified using the primer pairs CgEnd3-5Ffor (1F)/CgEnd3-5Frev(2R) and CgEnd3-3Ffor (2F)/CgEnd3-3Frev (3R), respectively. The full length of the Sur was amplified using primer pairs SUR-5'-M13F and SUR-3'-M13R, which included an approximately $20 \mathrm{bp}$ sequence that overlaps (M13F or M13R) the PCR products of the two flanking sequences of $C g E n d 3$. Second-round PCR was applied to generate the fusion constructs, and upstream and downstream flanking sequences were fused with two-thirds sulfonylurea resistance cassette, respectively.

To generate the deletion mutants of $C g E n d 3$, PEG-mediated transformation was used [54]. The resulting transformants were first screened on solid TB3 medium with $150 \mu \mathrm{g} / \mathrm{mL}$ sulfonylurea, and the putative $C g E n d 3$-deletion mutants were screened by PCR with the primers External-CgEnd3for (3F)/External-CgEnd3rev (4R) (Figure S2B) and primers Internal-CgEnd3for (4F)/Internal-CgEnd3rev (5R) (Figure S2C). For the complementation assay, the phleomycin resistance cassette (amplified from the $\mathrm{pBC}$-phleo vector provided by FGSC) was used as a selective marker, and the entire coding sequence of $C g E n d 3$, with approximately $1.5 \mathrm{~kb}$ upstream region, was transformed into the $C g E n d 3$ deletion mutant $(\triangle C g E n d 3-12)$. The complementation mutants were screened using InternalCgEnd3for (4F)/Internal-CgEnd3rev (5R) (Figure S2D). The complementation strain was described as $\Delta C g E n d 3 / E N D 3$ throughout this study. All primers used in this study are listed in Table 1. 
Table 1. Primers used in this study.

\begin{tabular}{|c|c|c|}
\hline Primer Name & Sequence & Use in This Study \\
\hline CgEnd3-5Ffor (1F) & AGACTGGCCAAAAGTGTTCG & 5F flanking sequence \\
\hline CgEnd3-5Frev (2R) & CTCCCACAGGAATCTCCGTC & \\
\hline CgEnd3-3Ffor (2F) & TACGCTTCGATACCCTTCGG & $3 \mathrm{~F}$ flanking sequence \\
\hline CgEnd3-3Frev (3R) & CTTGGAGCGACAAGTTGGGA & \\
\hline External-CgEnd3for (3F) & TTCCTAGCGACCCTGTTGTT & $\begin{array}{l}\text { External sequence used for } \\
\text { validation of mutant }\end{array}$ \\
\hline External-CgEnd3rev (4R) & GCCCGGTGAGTAGAATGGTA & \\
\hline Internal-CgEnd3for $(4 \mathrm{~F})$ & AATAACAACCCCGCСТCTTC & $\begin{array}{l}\text { Internal sequence used for } \\
\text { validation of mutant }\end{array}$ \\
\hline Internal-CgEnd3rev (5R) & AGCTGCTTCTTGAGCCTGAC & \\
\hline CgEnd3-Compfor & TCGACTCGACAACATCAAGC & Complementary sequence \\
\hline CgEnd3-Comprev & GCCCGGTGAGTAGAATGGTA & \\
\hline SUR-5'-M13F & CGCCAGGGTTTTCCCAGTCACGACGTCGACGTGCCAACGCCACAG & $\begin{array}{l}\text { Sur cassette contains the region of } \\
\text { M13F and M13R }\end{array}$ \\
\hline SUR-3'-M13R & AGCGGATAACAATTTCACACAGGAGTCGACGTGAGAGCATGCAAT & \\
\hline SU-SPLIT & CCAAGCATGTGCAGTGCCTTC & $\begin{array}{l}\text { The } 2 / 3 \text { rd portion of the Sur } \\
\text { cassette }\end{array}$ \\
\hline UR-SPLIT & GGAGGCCGACGTCATAGGCATC & \\
\hline CgPMC1-f & CATCATGATTGCTGGTCAGG & qRT-PCR of CgPMC1 \\
\hline CgPMC1-r & GACACCGAAAGGAATGGAAA & \\
\hline CgNCS1-f & AGCGACAAGTCAGGAAGCAT & qRT-PCR of CgNCS1 \\
\hline CgNCS1-r & CCTCGACGATCTTGAGCATT & \\
\hline CgCAM1-f & ACAACAACGGCTTCATCTCC & qRT-PCR of CgCAM1 \\
\hline CgCAM1-r & GCGAATCATCTCGTCAACCT & \\
\hline CgCRZ1-f & AGGTCGGATCTGCATCAAAC & qRT-PCR of CgCRZ1 \\
\hline CgCRZ1-r & ATGTACTGGCCGCTGGTATC & \\
\hline CgCAMK1-f & ATGCTGAAGAAGGGTCATGG & qRT-PCR of CgCAMK1 \\
\hline CgCAMK1-r & TGAAATCCTTGGCATCATCA & \\
\hline CgCHS1-f & GGTGGTGGTCTGAAGCGTTA & qRT-PCR of CgCHS1 \\
\hline CgCHS1-r & AGCGCATCTTGTGGAACTCA & \\
\hline $\mathrm{CgCHS} 2-\mathrm{f}$ & GACTACGCCCGCGAATATGA & qRT-PCR of $\mathrm{CgCHS} 2$ \\
\hline CgCHS2-r & GTTCGTAGATGCCGGAAGGA & \\
\hline CgCHS3-f & CACCGGCTACAGCGAGTATG & qRT-PCR of $\mathrm{CgCHS3}$ \\
\hline CgCHS3-r & CAAGTTTCCGCGGTACAGGA & \\
\hline CgCHS4-f & CGACAAGGACCATCCGAACT & qRT-PCR of CgCHS4 \\
\hline CgCHS4-r & GCGAGGCATCGGAGTAGTTA & \\
\hline CgCHS5-f & CTCAGGGCGGCATTGATACT & qRT-PCR of CgCHS5 \\
\hline CgCHS5-r & AGTAGAGCGTAGTTGGAGGC & \\
\hline CgCHS6-f & ACCAATCCGGTGCTTATCGG & qRT-PCR of $\mathrm{CgCHS} 6$ \\
\hline CgCHS6-r & GGGGTCTCGAAGCCAAGATG & \\
\hline CgCHS7-f & TGGTCAAGGGCCTTCAATGG & qRT-PCR of CgCHS7 \\
\hline CgCHS7-r & ATCACAACCTTTGGTGCGGA & \\
\hline CgDN3-f & CCTACTCGCTGTTCCCTTCA & qRT-PCR of CgDN3 \\
\hline CgDN3-r & CGTGGTCTCCCGGATAGTAG & \\
\hline CgEC6-f & TTGGCAGTATCACCGTGAAG & qRT-PCR of CgEC6 \\
\hline CgEC6-r & TCGATCTCATCCTGGTAGGC & \\
\hline CgFl-f & GCTGTTGAGTCCGGTGGTAT & qRT-PCR of $\mathrm{CgFl}$ \\
\hline CgFl-r & GGGTGGTGGTCATAGAGGTG & \\
\hline CgNis1-f & ATCTACGGCATTGCCTTCC & qRT-PCR of CgNis1 \\
\hline CgNis1-r & AGAAGGAGCCGATGACTGTG & \\
\hline Cg18S-f & GTGAGGCCCTCAAAGGTAGTGG & qRT-PCR of Cg18S \\
\hline Cg18S-r & GGATCCCAGTGCGAGACGT & \\
\hline
\end{tabular}

\subsection{Gene Expression Analysis}

To analyze the expression of calcium-signaling genes and chitin synthase genes, the RNA of each strain was first extracted. Fresh hyphae from WT and $\triangle C g E n d 3$ were cultured for 2 days using liquid $\mathrm{CM}$ under shaking environment at $25^{\circ} \mathrm{C}$. The total hyphae $(300 \mathrm{mg})$ from each strain was dried with filter paper and powdered using liquid nitrogen. Total RNA was extracted using TRIzol reagent (Invitrogen), following the manufacturer's instructions. To analyze the expression of core effectors during the early stage of infection, equal volumes $(30 \mu \mathrm{L})$ of conidial suspensions $\left(10^{6}\right.$ conidia $\left./ \mathrm{mL}\right)$ from WT and $\Delta C g E n d 3$ were inoculated on poplar leaves. Inoculated leaves were fixed on filter paper and placed into a $94 \mathrm{~mm}$ Petri dish containing $8 \mathrm{~mL}$ of sterile water; sterile cotton wool wetted with sterile water was used to cover the petioles of the leaves. Petri dishes were incubated at $25^{\circ} \mathrm{C}$. The inoculation 
area, including fungal tissue and leaf tissue, were cut at $3 \mathrm{dpi}$, and $5 \mathrm{mg}$ samples from WT and $\triangle C g E n d 3$ area were collected and powdered using liquid nitrogen, respectively. Total RNA was extracted using TRIzol reagent (Invitrogen), following the manufacturer's instructions. Then, $0.8 \%$ agarose gel was applied to test the RNA integrity. Additionally, cDNAs were synthesized using the FastKing cDNA synthesis kit (Tiangen, China). The Cg18S gene served as an internal reference in this study. The Bio-Rad CFX96 PCR system (Bio-Rad, Hercules, CA, USA) was used to analyze the expression of related genes in this study. Relative gene expression in this study was calculated using the $2^{-\Delta \Delta C T}$ method [95]. Each experiment was performed three times.

\subsection{Fungicide Response Assay}

To test the response to fungicide, two broad-spectrum fungicides, difenoconazole and fludioxonil, were tested in this study. Difenoconazole and fludioxonil were dissolved in acetone at a concentration of $1 \mathrm{mg} / \mathrm{mL}$. Hyphal blocks of each strain were inoculated on PDA mixed with difenoconazole $(0.8 \mu \mathrm{g} / \mathrm{mL})$ and fludioxonil ( 5 and $10 \mu \mathrm{g} / \mathrm{mL})$, respectively. Plates were cultured at $25^{\circ} \mathrm{C}$. This experiment was performed three times.

\subsection{Cellophane Membrane Penetration Assays}

To test the penetration ability of each strain, hyphal blocks from each strain were inoculated on the sterile cellophane membrane overlaid on PDA plates. The cellophane membrane was cut into a size of $3 \times 3 \mathrm{~cm}$. Plates were cultured at $25^{\circ} \mathrm{C}$ for 2 days (Pre). At $2 \mathrm{dpi}$, the entire membrane with colony was removed, and the resulting plates were cultured at $25^{\circ} \mathrm{C}$ for 2 days (Post). This experiment was performed with three biological replicates and five technical replicates for each treatment.

\subsection{Pathogenicity Assay}

To determine the pathogenicity of WT and $C g E n d 3$ deletion mutant, the susceptible species Populus $\times$ beijingensis was used as a host throughout this study. Annual poplar branches were cultured in water and poplar leaves detached from two-week-old watercultivated poplar branches. To remove microorganisms and dust on the surface of the leaves, poplar leaves were dipped in $75 \%$ ethyl alcohol for $10 \mathrm{~s}$ and thoroughly washed with sterile water. Equal volumes $(30 \mu \mathrm{L})$ of conidial suspensions $\left(2 \times 10^{5}\right.$ conidia $\left./ \mathrm{mL}\right)$ from each strain were inoculated on poplar leaves. Inoculated leaves were fixed on filter paper and placed into a $94 \mathrm{~mm}$ Petri dish containing $8 \mathrm{~mL}$ of sterile water, and wettened sterile cotton wool was used to cover the petioles of the leaves. Petri dishes were incubated at $25^{\circ} \mathrm{C}$. Symptoms were pictured from $4-8 \mathrm{dpi}$. Lesion size was measured using quadrille paper. This experiment was performed with three biological replicates and five technical replicates for each treatment.

\subsection{DAB and FM4-64 Staining}

Conidia of the WT, $\Delta C g E n d 3$, and $\Delta C g E n d 3 / E N D 3$ were resuspended in sterilized deionized water $\left(10^{5}\right.$ conidia/mL). Conidial suspensions $(30 \mu \mathrm{L})$ of each strain were inoculated on the hydrophobic surfaces of onion epidermal cells. Inoculated samples were fixed on filter paper and placed into a $94 \mathrm{~mm}$ Petri dish containing $8 \mathrm{~mL}$ of sterile water and incubated at $25^{\circ} \mathrm{C}$. DAB was used to detect the accumulation of ROS. In the presence of ROS, DAB is converted to dark brown polymers. At $9 \mathrm{hpi}$, the accumulation of ROS was stained with $2 \mathrm{mg} / \mathrm{mL}$ DAB $(30 \mu \mathrm{L})$ for $12 \mathrm{~h}$ under darkness. The intensities of dark brown polymers were quantified using ImageJ software, and at least 10 appressoria were analyzed from each strain. This experiment was performed with three biological replicates and five technical replicates for each treatment.

FM4-64 (Thermo fisher, Waltham, MA, USA) was dissolved in sterile water at the final concentration of $5 \mu \mathrm{M}$. Hyphal block from WT, $\Delta C g E n d 3$, and $\Delta C g E n d 3 /$ END3 were inoculated on PDA-coated glass slides, and samples were incubated at $25{ }^{\circ} \mathrm{C}$. Then, at $2 \mathrm{dpi}$, the radiate hyphae were stained with FM4-64. The samples were observed under a 
fluorescence microscope immediately. Excitation spectra: $535 \pm 20 \mathrm{~nm}$, emission spectra: $610 \pm 30 \mathrm{~nm}$. Images were pictured from 0 to $30 \mathrm{~min}$. This experiment was performed with three biological replicates and five technical replicates for each treatment. To analyze the intensities of endocytosis, the fluorescence intensities in the cytoplasm at each of the time points were quantified using ImageJ software; at least 10 samples were analyzed from each strain. This experiment was performed with three biological replicates and five technical replicates for each treatment.

Supplementary Materials: The following are available online at https:/ /www.mdpi.com/article/10 .3390/ijms22084029/s1.

Author Contributions: Conceptualization, Methodology, Writing—Original draft preparation, X.W.; Data curation, Visualization D.L.; Project administration, Funding acquisition, Validation, WritingReviewing and Editing C.T. All authors have read and agreed to the published version of the manuscript.

Funding: The research was supported by the National Key Research and Development Program (2017YFD0600100) and National Natural Science Foundation of China (32071767).

Institutional Review Board Statement: Not applicable.

Informed Consent Statement: Not applicable.

Data Availability Statement: The data presented in this study are available in " $\mathrm{CgEnd} 3$ regulates endocytosis, appressorium formation and virulence in the poplar anthracnose fungus Colletotrichum gloeosporioides".

Acknowledgments: We gratefully acknowledge Richard Wilson, University of Nebraska-Lincoln for the donation of plasmid PCB1523.

Conflicts of Interest: The authors declare no conflict of interest.

\section{References}

1. Kim, J.W.; Shim, S.H. The fungus Colletotrichum as a source for bioactive secondary metabolites. Arch. Pharmacal Res. 2019, 42, 735-753. [CrossRef]

2. Li, Z.; Liang, Y.-M.; Tian, C. Characterization of the causal agent of poplar anthracnose occurring in the Beijing region. Mycotaxon 2012, 120, 277-286. [CrossRef]

3. Xu, X.; Wang, Y.; Tian, C.; Liang, Y. The Colletotrichum gloeosporioides RhoB regulates cAMP and stress response pathways and is required for pathogenesis. Fungal Genet. Biol. B 2016, 96, 12-24. [CrossRef]

4. Sun, Y.; Wang, Y.; Tian, C. bZIP transcription factor CgAP1 is essential for oxidative stress tolerance and full virulence of the poplar anthracnose fungus Colletotrichum gloeosporioides. Fungal Genet. Biol. B 2016, 95, 58-66. [CrossRef]

5. Talbot, N. Appressoria. Curr. Biol. 2019, 29, R144-R146. [CrossRef]

6. Zhang, X.; Zhang, J.; He-Pu, H.; Wang, X.; Tian, C. Histopathology study of poplar leaves infected by Colletotrichum gloeosporioides. Beijing Linye Daxue Xuebao/J. Beijing For. Univ. 2018, 40, 101-109. [CrossRef]

7. Kumamoto, C.A. Molecular mechanisms of mechanosensing and their roles in fungal contact sensing. Nat. Rev. Microbiol. 2008, 6, 667-673. [CrossRef] [PubMed]

8. DeZwaan, T.M.; Carroll, A.M.; Valent, B.; Sweigard, J.A. Magnaporthe grisea pth11p is a novel plasma membrane protein that mediates appressorium differentiation in response to inductive substrate cues. Plant Cell 1999, 11, 2013-2030. [CrossRef] [PubMed]

9. Kou, Y.; Tan, Y.H.; Ramanujam, R.; Naqvi, N.I. Structure-function analyses of the Pth11 receptor reveal an important role for CFEM motif and redox regulation in rice blast. New Phytol. 2017, 214, 330-342. [CrossRef]

10. Lanver, D.; Mendoza-Mendoza, A.; Brachmann, A.; Kahmann, R. Sho1 and Msb2-related proteins regulate appressorium development in the smut fungus Ustilago maydis. Plant Cell 2010, 22, 2085-2101. [CrossRef]

11. Liu, W.; Zhou, X.; Li, G.; Li, L.; Kong, L.; Wang, C.; Zhang, H.; Xu, J.R. Multiple plant surface signals are sensed by different mechanisms in the rice blast fungus for appressorium formation. PLoS Pathog. 2011, 7, e1001261. [CrossRef]

12. Saunders, D.G.; Aves, S.J.; Talbot, N.J. Cell cycle-mediated regulation of plant infection by the rice blast fungus. Plant Cell 2010, 22, 497-507. [CrossRef] [PubMed]

13. Castanheira, S.; Mielnichuk, N.; Pérez-Martín, J. Programmed cell cycle arrest is required for infection of corn plants by the fungus Ustilago maydis. Development 2014, 141, 4817-4826. [CrossRef] [PubMed]

14. Veneault-Fourrey, C.; Barooah, M.; Egan, M.; Wakley, G.; Talbot, N.J. Autophagic fungal cell death is necessary for infection by the rice blast fungus. Science 2006, 312, 580-583. [CrossRef]

15. Wang, Z.Y.; Jenkinson, J.M.; Holcombe, L.J.; Soanes, D.M.; Veneault-Fourrey, C.; Bhambra, G.K.; Talbot, N.J. The molecular biology of appressorium turgor generation by the rice blast fungus Magnaporthe grisea. Biochem. Soc. Trans. 2005, 33, 384-388. [CrossRef] 
16. Money, N.; Howard, R. Confirmation of a Link between Fungal Pigmentation, Turgor Pressure, and Pathogenicity Using a New Method of Turgor Measurement. Fungal Genet. Biol. 1996, 20, 217-227. [CrossRef]

17. Chumley, F.; Valent, B. Genetic analysis of melanin-deficient, nonpathogenic mutants of Magnaporthe grisea. Mol. Plant-Microbe Interact. 1990, 3, 135-143. [CrossRef]

18. Ryder, L.; Dagdas, Y.; Kershaw, M.; Venkataraman, C.; Madzvamuse, A.; Yan, X.; Cruz-Mireles, N.; Soanes, D.; Oses-Ruiz, M.; Styles, V.; et al. A sensor kinase controls turgor-driven plant infection by the rice blast fungus. Nature 2019, 574, 1-5. [CrossRef]

19. Huser, A.; Takahara, H.; Schmalenbach, W.; O'Connell, R. Discovery of pathogenicity genes in the crucifer anthracnose fungus Colletotrichum higginsianum, using random insertional mutagenesis. Mol. Plant Microbe Interact. 2009, 22, 143-156. [CrossRef]

20. Takano, Y.; Kubo, Y.; Kuroda, I.; Furusawa, I. Temporal Transcriptional Pattern of Three Melanin Biosynthesis Genes, PKS1, SCD1, and THR1, in Appressorium-Differentiating and Nondifferentiating Conidia of Colletotrichum lagenarium. Appl. Environ. Microbiol. 1997, 63, 351-354. [CrossRef]

21. Perpetua, N.S.; Kubo, Y.; Yasuda, N.; Takano, Y.; Furusawa, I. Cloning and characterization of a melanin biosynthetic THR1 reductase gene essential for appressorial penetration of Colletotrichum lagenarium. Mol. Plant Microbe Interact. 1996, 9, 323-329. [CrossRef]

22. Kubo, Y. Cloning of a Melanin Biosynthetic Gene Essential for Appressorial Penetration of Colletotrichum lagenarium. Mol. Plant-Microbe Interact. 1991, 4, 440. [CrossRef]

23. Kubo, Y.; Takano, Y.; Endo, N.; Yasuda, N.; Tajima, S.; Furusawa, I. Cloning and structural analysis of the melanin biosynthesis gene SCD1 encoding scytalone dehydratase in Colletotrichum lagenarium. Appl. Environ. Microbiol. 1997, 62, 4340-4344. [CrossRef]

24. Wang, T.; Ren, D.; Guo, H.; Chen, X.; Zhu, P.; Nie, H.; Xu, L. CgSCD1 Is Essential for Melanin Biosynthesis and Pathogenicity of Colletotrichum gloeosporioides. Pathogens 2020, 9, 141. [CrossRef]

25. Kleemann, J.; Rincon-Rivera, L.J.; Takahara, H.; Neumann, U.; Ver Loren van Themaat, E.; van der Does, H.C.; Hacquard, S.; Stüber, K.; Will, I.; Schmalenbach, W.; et al. Sequential delivery of host-induced virulence effectors by appressoria and intracellular hyphae of the phytopathogen Colletotrichum higginsianum. PLoS Pathog. 2012, 8, e1002643. [CrossRef]

26. Irieda, H.; Maeda, H.; Akiyama, K.; Hagiwara, A.; Saitoh, H.; Uemura, A.; Terauchi, R.; Takano, Y. Colletotrichum orbiculare Secretes Virulence Effectors to a Biotrophic Interface at the Primary Hyphal Neck via Exocytosis Coupled with SEC22-Mediated Traffic. Plant Cell 2014, 26, 2265-2281. [CrossRef] [PubMed]

27. Giraldo, M.C.; Dagdas, Y.F.; Gupta, Y.K.; Mentlak, T.A.; Yi, M.; Martinez-Rocha, A.L.; Saitoh, H.; Terauchi, R.; Talbot, N.J.; Valent, B. Two distinct secretion systems facilitate tissue invasion by the rice blast fungus Magnaporthe oryzae. Nat. Commun. 2013, 4, 1996. [CrossRef] [PubMed]

28. Wilson, R.A.; Talbot, N.J. Under pressure: Investigating the biology of plant infection by Magnaporthe oryzae. Nat. Rev. Microbiol. 2009, 7, 185-195. [CrossRef]

29. Carafoli, E. Calcium signaling: A tale for all seasons. Proc. Natl. Acad. Sci. USA 2002, 99, 1115-1122. [CrossRef]

30. Wachten, D.; Roderick, H.; Bootman, M. Intracellular Calcium Signaling. Handb. Cell Signal. 2010, 2, 937-942. [CrossRef]

31. Chin, D.; Means, A. Calmodulin: A prototypical calcium sensor. Trends Cell Biol. 2000, 10, 322-328. [CrossRef]

32. Harel, A.; Bercovich, S.; Yarden, O. Calcineurin is required for sclerotial development and pathogenicity of Sclerotinia sclerotiorum in an oxalic acid-independent manner. Mol. Plant Microbe Interact. 2006, 19, 682-693. [CrossRef] [PubMed]

33. Hernández-Ortiz, P.; Espeso, E.A. Phospho-regulation and nucleocytoplasmic trafficking of CrzA in response to calcium and alkaline-pH stress in Aspergillus nidulans. Mol. Microbiol. 2013, 89, 532-551. [CrossRef]

34. Park, H.S.; Lee, S.C.; Cardenas, M.E.; Heitman, J. Calcium-Calmodulin-Calcineurin Signaling: A Globally Conserved Virulence Cascade in Eukaryotic Microbial Pathogens. Cell Host Microbe 2019, 26, 453-462. [CrossRef] [PubMed]

35. Choi, J.; Kim, Y.; Kim, S.; Park, J.; Lee, Y.H. MoCRZ1, a gene encoding a calcineurin-responsive transcription factor, regulates fungal growth and pathogenicity of Magnaporthe oryzae. Fungal Genet. Biol. B 2009, 46, 243-254. [CrossRef] [PubMed]

36. Xiong, D.; Wang, Y.; Tang, C.; Fang, Y.; Zou, J.; Tian, C. VdCrz1 is involved in microsclerotia formation and required for full virulence in Verticillium dahliae. Fungal Genet. Biol. B 2015, 82, 201-212. [CrossRef]

37. Schumacher, J.; de Larrinoa, I.F.; Tudzynski, B. Calcineurin-responsive zinc finger transcription factor CRZ1 of Botrytis cinerea is required for growth, development, and full virulence on bean plants. Eukaryot. Cell 2008, 7, 584-601. [CrossRef]

38. Adamíková, L.; Straube, A.; Schulz, I.; Steinberg, G. Calcium signaling is involved in dynein-dependent microtubule organization. Mol. Biol. Cell 2004, 15, 1969-1980. [CrossRef]

39. Nguyen, Q.B.; Kadotani, N.; Kasahara, S.; Tosa, Y.; Mayama, S.; Nakayashiki, H. Systematic functional analysis of calciumsignalling proteins in the genome of the rice-blast fungus, Magnaporthe oryzae, using a high-throughput RNA-silencing system. Mol. Microbiol. 2008, 68, 1348-1365. [CrossRef]

40. Peñalva, M. Endocytosis in filamentous fungi: Cinderella gets her reward. Curr. Opin. Microbiol. 2010, 13, 684-692. [CrossRef]

41. Fischer-Parton, S.; Parton, R.M.; Hickey, P.C.; Dijksterhuis, J.; Atkinson, H.A.; Read, N.D. Confocal microscopy of FM4-64 as a tool for analysing endocytosis and vesicle trafficking in living fungal hyphae. J. Microsc. 2000, 198, 246-259. [CrossRef] [PubMed]

42. Wesp, A.; Hicke, L.; Palecek, J.; Lombardi, R.; Aust, T.; Munn, A.L.; Riezman, H. End4p/Sla2p interacts with actin-associated proteins for endocytosis in Saccharomyces cerevisiae. Mol. Biol. Cell 1997, 8, 2291-2306. [CrossRef] [PubMed]

43. Yang, S.; Cope, M.J.; Drubin, D.G. Sla2p is associated with the yeast cortical actin cytoskeleton via redundant localization signals. Mol. Biol. Cell 1999, 10, 2265-2283. [CrossRef] [PubMed] 
44. Coccetti, P.; Nicastro, R.; Tripodi, F. Conventional and emerging roles of the energy sensor Snf1/AMPK in Saccharomyces cerevisiae. Microb. Cell 2018, 5, 482-494. [CrossRef] [PubMed]

45. Tang, H.Y.; Munn, A.; Cai, M. EH domain proteins Pan1p and End3p are components of a complex that plays a dual role in organization of the cortical actin cytoskeleton and endocytosis in Saccharomyces cerevisiae. Mol. Cell. Biol. 1997, 17, 4294-4304. [CrossRef] [PubMed]

46. Sun, Y.; Leong, N.; Wong, T.; Drubin, D. A Pan1/End3/Sla1 complex links Arp2/3-mediated actin assembly to sites of clathrinmediated endocytosis. Mol. Biol. Cell 2015, 26. [CrossRef] [PubMed]

47. Bénédetti, H.; Raths, S.; Crausaz, F.; Riezman, H. The END3 gene encodes a protein that is required for the internalization step of endocytosis and for actin cytoskeleton organization in yeast. Mol. Biol. Cell 1994, 5, 1023-1037. [CrossRef]

48. Vanstreels, E.; Alamar, C.; Verlinden, B.; Enninghorst, A.; Loodts, J.K.A.; Tijskens, E.; Ramon, H.; Nicolaï, B. Micromechanical behaviour of onion epidermal tissue. Postharvest Biol. Technol. 2005, 37, 163-173. [CrossRef]

49. Park, G.; Bruno, K.; Staiger, C.; Talbot, N.; Xu, J.-R. Independent genetic mediate turgor generation and penetration peg formation during plant infection in the rice blast fungus Magnaporthe grisea. Mol. Microbiol. 2004, 53, 1695-1707. [CrossRef]

50. Gu, Q.; Chen, Y.; Liu, Y.; Zhang, C.; Ma, Z. The transmembrane protein FgSho1 regulates fungal development and pathogenicity via the MAPK module Ste50-Ste11-Ste7 in Fusarium graminearum. New Phytol. 2014, 206. [CrossRef]

51. Yu, J.; Li, T.; Tian, L.; Tang, C.; Klosterman, S.; Tian, C.; Wang, Y. Two Verticillium dahliae MAPKKKs, VdSsk2 and VdSte11, Have Distinct Roles in Pathogenicity, Microsclerotial Formation, and Stress Adaptation. mSphere 2019, 4. [CrossRef]

52. He, P.; Wang, Y.; Wang, X.; Zhang, X.; Tian, C. The Mitogen-Activated Protein Kinase CgMK1 Governs Appressorium Formation, Melanin Synthesis, and Plant Infection of Colletotrichum gloeosporioides. Front. Microbiol. 2017, 8, 2216. [CrossRef] [PubMed]

53. Apostol, I.; Heinstein, P.F.; Low, P.S. Rapid Stimulation of an Oxidative Burst during Elicitation of Cultured Plant Cells: Role in Defense and Signal Transduction. Plant Physiol. 1989, 90, 109-116. [CrossRef] [PubMed]

54. Wang, X.; Xu, X.; Liang, Y.-M.; Wang, Y.; Tian, C. A Cdc42 homolog in Colletotrichum gloeosporioides regulates morphological development and is required for ROS-mediated plant infection. Curr. Genet. 2018, 64. [CrossRef] [PubMed]

55. Stephenson, S.A.; Hatfield, J.; Rusu, A.G.; Maclean, D.J.; Manners, J.M. CgDN3: An essential pathogenicity gene of colletotrichum gloeosporioides necessary to avert a hypersensitive-like response in the host Stylosanthes guianensis. Mol. Plant Microbe Interact. 2000, 13, 929-941. [CrossRef] [PubMed]

56. O'Connell, R.J.; Thon, M.R.; Hacquard, S.; Amyotte, S.G.; Kleemann, J.; Torres, M.F.; Damm, U.; Buiate, E.A.; Epstein, L.; Alkan, $\mathrm{N}$; ; et al. Lifestyle transitions in plant pathogenic Colletotrichum fungi deciphered by genome and transcriptome analyses. Nat. Genet. 2012, 44, 1060-1065. [CrossRef] [PubMed]

57. Sanz-Martín, J.M.; Pacheco-Arjona, J.R.; Bello-Rico, V.; Vargas, W.A.; Monod, M.; Díaz-Mínguez, J.M.; Thon, M.R.; Sukno, S.A. A highly conserved metalloprotease effector enhances virulence in the maize anthracnose fungus Colletotrichum graminicola. Mol. Plant Pathol. 2016, 17, 1048-1062. [CrossRef]

58. Yoshino, K.; Irieda, H.; Sugimoto, F.; Yoshioka, H.; Okuno, T.; Takano, Y. Cell death of Nicotiana benthamiana is induced by secreted protein NIS1 of Colletotrichum orbiculare and is suppressed by a homologue of CgDN3. Mol. Plant Microbe Interact. 2012, 25, 625-636. [CrossRef]

59. Yap, K.L.; Ames, J.B.; Swindells, M.B.; Ikura, M. Diversity of conformational states and changes within the EF-hand protein superfamily. Proteins 1999, 37, 499-507. [CrossRef]

60. Weiss, J.; Burgoyne, R. EF-Hand Proteins and Calcium Sensing; Elsevier: Amsterdam, The Netherlands, 2003; Volume 2, pp. 79-82.

61. Lee, S.C.; Lee, Y.H. Calcium/calmodulin-dependent signaling for appressorium formation in the plant pathogenic fungus Magnaporthe grisea. Mol. Cells 1998, 8, 698-704.

62. Uhm, K.H.; Ahn, I.P.; Kim, S.; Lee, Y.H. Calcium/Calmodulin-Dependent Signaling for Prepenetration Development in Colletotrichum gloeosporioides. Phytopathology 2003, 93, 82-87. [CrossRef]

63. Rogers, H.; Perkins, H.; Ward, J. Cell Walls of Filamentous Fungi; ASM Press: Washington, DC, USA, $1980 ;$ pp. $469-477$.

64. Yang, J.; Zhang, K.Q. Chitin Synthesis and Degradation in Fungi: Biology and Enzymes. Adv. Exp. Med. Biol. 2019, $1142,153-167$. [CrossRef] [PubMed]

65. Rodríguez-Quiñones, J.F.; Rodríguez-Medina, J.R. Differential gene expression signatures for cell wall integrity found in chitin synthase II (chs2Delta) and myosin II (myo1Delta) deficient cytokinesis mutants of Saccharomyces cerevisiae. BMC Res. Notes 2009, 2, 87. [CrossRef] [PubMed]

66. Zhang, J.; Jiang, H.; Du, Y.; Keyhani, N.O.; Xia, Y. Members of chitin synthase family in Metarhizium acridum differentially affect fungal growth, stress tolerances, cell wall integrity and virulence. PLoS Pathog. 2019, 15, e1007964. [CrossRef] [PubMed]

67. Zhang, Y.Z.; Chen, Q.; Liu, C.H.; Liu, Y.B.; Yi, P.; Niu, K.X.; Wang, Y.Q.; Wang, A.Q.; Yu, H.Y.; Pu, Z.E.; et al. Chitin synthase gene FgCHS8 affects virulence and fungal cell wall sensitivity to environmental stress in Fusarium graminearum. Fungal Biol. 2016, 120, 764-774. [CrossRef]

68. Soulié, M.C.; Piffeteau, A.; Choquer, M.; Boccara, M.; Vidal-Cros, A. Disruption of Botrytis cinerea class I chitin synthase gene Bcchs1 results in cell wall weakening and reduced virulence. Fungal Genet. Biol. B. 2003, 40, 38-46. [CrossRef]

69. Juvvadi, P.; Lee, S.C.; Heitman, J.; Steinbach, W. Calcineurin in Fungal Virulence and Drug Resistance: Prospects for Harnessing Targeted Inhibition of Calcineurin for an Antifungal Therapeutic Approach. Virulence 2016, 8, 186-197. [CrossRef] [PubMed]

70. Li, Y.; He, P.; Tian, C.; Wang, Y. CgHog1 controls the adaptation to both sorbitol and fludioxonil in Colletotrichum gloeosporioides. Fungal Genet. Biol. B 2020, 135, 103289. [CrossRef] 
71. Tang, H.; Xu, J.; Mingjie, C. Pan1p, End3p, and Sla1p, Three Yeast Proteins Required for Normal Cortical Actin Cytoskeleton Organization, Associate with Each Other and Play Essential Roles in Cell Wall Morphogenesis. Mol. Cell. Biol. 2000, $20,12-25$. [CrossRef]

72. Li, X.; Gao, C.; Li, L.; Liu, M.; Yin, Z.; Zhang, H.; Zheng, X.; Wang, P.; Zhang, Z. MoEnd3 regulates appressorium formation and virulence through mediating endocytosis in rice blast fungus Magnaporthe oryzae. PLoS Pathog. 2017, 13, e1006449. [CrossRef]

73. Wessels, J.G.H. Cell Wall Synthesis in Apical Hyphal Growth. Int. Rev. Cytol. 1986, 104, 37-79. [CrossRef]

74. Chuang, J.S.; Schekman, R.W. Differential trafficking and timed localization of two chitin synthase proteins, Chs2p and Chs3p. J. Cell Biol. 1996, 135, 597-610. [CrossRef]

75. Wedlich-Söldner, R.; Bölker, M.; Kahmann, R.; Steinberg, G. A putative endosomal t-SNARE links exo- and endocytosis in the phytopathogenic fungus Ustilago maydis. EMBO J. 2000, 19, 1974-1986. [CrossRef] [PubMed]

76. Perez-Nadales, E.; Di Pietro, A. The transmembrane protein Sho1 cooperates with the mucin Msb2 to regulate invasive growth and plant infection in Fusarium oxysporum. Mol. Plant Pathol. 2015, 16, 593-603. [CrossRef]

77. Fuchs, B.B.; Mylonakis, E. Our paths might cross: The role of the fungal cell wall integrity pathway in stress response and cross talk with other stress response pathways. Eukaryot. Cell 2009, 8, 1616-1625. [CrossRef]

78. Levin, D.E. Cell wall integrity signaling in Saccharomyces cerevisiae. Microbiol. Mol. Biol. Rev. 2005, 69, 262-291. [CrossRef]

79. Zhang, X.; Liu, W.; Li, Y.; Li, G.; Xu, J.R. Expression of HopAI interferes with MAP kinase signalling in Magnaporthe oryzae. Environ. Microbiol. 2017, 19, 4190-4204. [CrossRef]

80. $\mathrm{Xu}$, J.R.; Staiger, C.J.; Hamer, J.E. Inactivation of the mitogen-activated protein kinase Mps1 from the rice blast fungus prevents penetration of host cells but allows activation of plant defense responses. Proc. Natl. Acad. Sci. USA 1998, 95, 12713-12718. [CrossRef] [PubMed]

81. Yong, H.Y.; Abu Bakar, F.; Illias, R.; Mahadi, N.M.; Abdul Murad, A.M. Cgl-SLT2 is required for appressorium formation, sporulation and pathogenicity in Colletotrichum gloeosporioide. Braz. J. Microbiol. 2013, 44, 1241-1250. [CrossRef] [PubMed]

82. Nan, Z.; Zhi-Qiang, L.; Man-Li, W.U.; Xiao-Yu, L.I. Gene cloning and functional analysis of CgSho1 in Colletotrichum gloeosporioides. Acta Phytopathol. Sin. 2017, 47, 40-49. [CrossRef]

83. Choi, J.; Kim, K.S.; Rho, H.S.; Lee, Y.H. Differential roles of the phospholipase C genes in fungal development and pathogenicity of Magnaporthe oryzae. Fungal Genet. Biol. B 2011, 48, 445-455. [CrossRef] [PubMed]

84. Jiang, L.; Wang, J.; Asghar, F.; Snyder, N.; Cunningham, K.W. CaGdt1 plays a compensatory role for the calcium pump CaPmr1 in the regulation of calcium signaling and cell wall integrity signaling in Candida albicans. Cell Commun. Signal. 2018, 16, 33. [CrossRef]

85. Blankenship, J.R.; Wormley, F.L.; Boyce, M.K.; Schell, W.A.; Filler, S.G.; Perfect, J.R.; Heitman, J. Calcineurin is essential for Candida albicans survival in serum and virulence. Eukaryot. Cell 2003, 2, 422-430. [CrossRef]

86. Chen, Y.-L.; Lehman, V.N.; Lewit, Y.; Averette, A.F.; Heitman, J. Calcineurin governs thermotolerance and virulence of Cryptococcus gattii. G3 (Bethesda) 2013, 3, 527-539. [CrossRef] [PubMed]

87. Lamoth, F.; Juvvadi, P.R.; Gehrke, C.; Steinbach, W.J. In vitro activity of calcineurin and heat shock protein 90 Inhibitors against Aspergillus fumigatus azole- and echinocandin-resistant strains. Antimicrob. Agents Chemother. 2013, 57, 1035-1039. [CrossRef]

88. Fudal, I.; Collemare, J.; Böhnert, H.U.; Melayah, D.; Lebrun, M.H. Expression of Magnaporthe grisea avirulence gene ACE1 is connected to the initiation of appressorium-mediated penetration. Eukaryot. Cell 2007, 6, 546-554. [CrossRef]

89. Pérez-Nadales, E.; Di Pietro, A. The membrane mucin Msb2 regulates invasive growth and plant infection in Fusarium oxysporum. Plant Cell 2011, 23, 1171-1185. [CrossRef] [PubMed]

90. Zhang, J.; Zhang, Y.; Yang, J.; Kang, L.; Elo, R.A.; Zhou, H.; Zhao, J. The $\alpha-1,6$-mannosyltransferase VdOCH1 plays a major role in microsclerotium formation and virulence in the soil-borne pathogen Verticillium dahliae. Fungal Biol. 2019, 123, 539-546. [CrossRef]

91. Tamura, K.; Stecher, G.; Peterson, D.; Filipski, A.; Kumar, S. MEGA6: Molecular Evolutionary Genetics Analysis version 6.0. Mol. Biol. Evol. 2013, 30, 2725-2729. [CrossRef]

92. Patnaik, S.R.; Raghupathy, R.K.; Zhang, X.; Mansfield, D. The Role of RPGR and Its Interacting Proteins in Ciliopathies. J. Ophthalmol. 2015, 2015, 414781. [CrossRef]

93. Wilson, R.; Gibson, R.; Quispe, C.; Littlechild, J.; Talbot, N. An NADPH-Dependent Genetic Switch Regulates Plant Infection by the Rice Blast Fungus. Proc. Natl. Acad. Sci. USA 2010, 107, 21902-21907. [CrossRef] [PubMed]

94. Sweigard, J.; Carroll, A.; Farrall, L.; Valent, B. A series of vectors for fungaltransformation. Fungal Genet. Rep. 1997, 44, 52-53. [CrossRef]

95. Livak, K.J.; Schmittgen, T.D. Analysis of relative gene expression data using real-time quantitative PCR and the 2(-Delta Delta C(T)) Method. Methods 2001, 25, 402-408. [CrossRef] [PubMed] 